\title{
Electron lenses for head-on beam-beam compensation in RHIC
}

X. Gu, W. Fischer, Z. Altinbas, M. Anerella, E. Bajon, M. Bannon, D. Bruno, M. Costanzo,

A. Drees, D. M. Gassner, R. C. Gupta, J. Hock, M. Harvey, A. K. Jain, J. P. Jamilkowski,

P. Kankiya, R. Lambiase, C. Liu, Y. Luo, M. Mapes, A. Marusic, C. Mi, R. Michnoff,

T. A. Miller, M. Minty, S. Nemesure, W. Ng, D. Phillips, A. I. Pikin, P. J. Rosas,

G. Robert-Demolaize, T. Samms, J. Sandberg, V. Schoefer, T. C. Shrey, Y. Tan, R. Than,

C. Theisen, P. Thieberger, J. Tuozzolo, P. Wanderer, and W. Zhang

Brookhaven National Laboratory, Upton, New York 11973, USA

S. M. White

European Synchrotron Radiation Facility, B.P. 220, 38043 Grenoble Cedex, France

(Received 22 November 2016; published 17 February 2017)

Two electron lenses (e-lenses) have been in operation during the 2015 RHIC physics run as part of a head-on beam-beam compensation scheme. While the RHIC lattice was chosen to reduce the beam-beaminduced resonance-driving terms, the electron lenses reduced the beam-beam-induced tune spread. This has been demonstrated for the first time. The beam-beam compensation scheme allows for higher beam-beam parameters and therefore higher intensities and luminosity. In this paper, we detail the design considerations and verification of the electron beam parameters of the RHIC $e$-lenses. Longitudinal and transverse alignments with ion beams and the transverse beam transfer function measurement with head-on electronproton beam are presented.

DOI: 10.1103/PhysRevAccelBeams.20.023501

\section{INTRODUCTION}

To compensate for the beam-beam effects from the proton-proton interactions at the two interaction points in the Relativistic Heavy Ion Collider (RHIC) of Brookhaven National Laboratory, a beam-beam compensation scheme has been implemented and made fully operational in 2015 [1]. This scheme includes two electron lenses (e-lenses). The beam-beam compensation in conjunction with the intensity upgrade in the injectors [2] led to an increase of the proton bunch intensity in the RHIC [3,4] as well as increases of the beam-beam parameter and the peak and the average luminosities [1,5].

After the first experiments at the four-beam collider Dispositif de Collisions dans l'Igloo (DCI) [6], head-on beam-beam compensation using electron lenses had been proposed for the superconducting supercollider (SSC) [7], Tevatron [8], and LHC [9]. Two electron lenses were installed in the Tevatron $[10,11]$ that improved the lifetime of colliding bunches in tests [12] and were routinely used as abort gap cleaners [13]. The Tevatron electron lenses were also used in beam-beam compensation studies [14] and as a

\footnotetext{
Corresponding author. xgu@bnl.gov

Published by the American Physical Society under the terms of the Creative Commons Attribution 4.0 International license. Further distribution of this work must maintain attribution to the author(s) and the published article's title, journal citation, and DOI.
}

hollow electron lens for halo scraping [15]. Recently, an $e$ lens has also been proposed at the LHC to control beam halo [16] and, at the Integrable Optics Test Accelerator (IOTA), a ring to demonstrate a nonlinear integrable lattice [17].

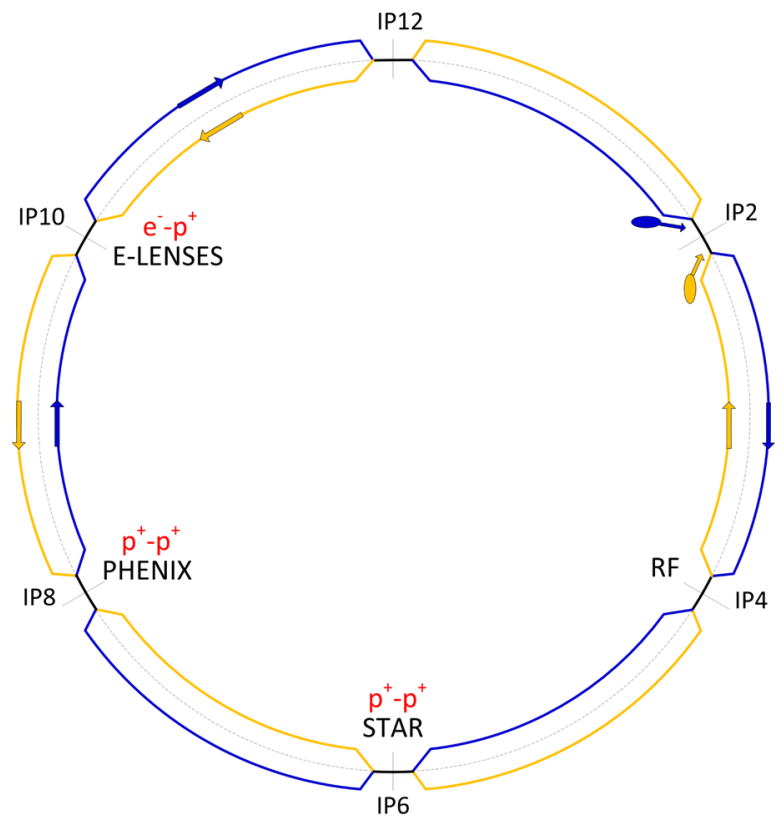

FIG. 1. The layout for head-on beam-beam compensation in the RHIC. Head-on proton-proton beam-beam interactions occur in IP6 and IP8, while head-on electron-proton beam-beam compensation is achieved in IP10. 

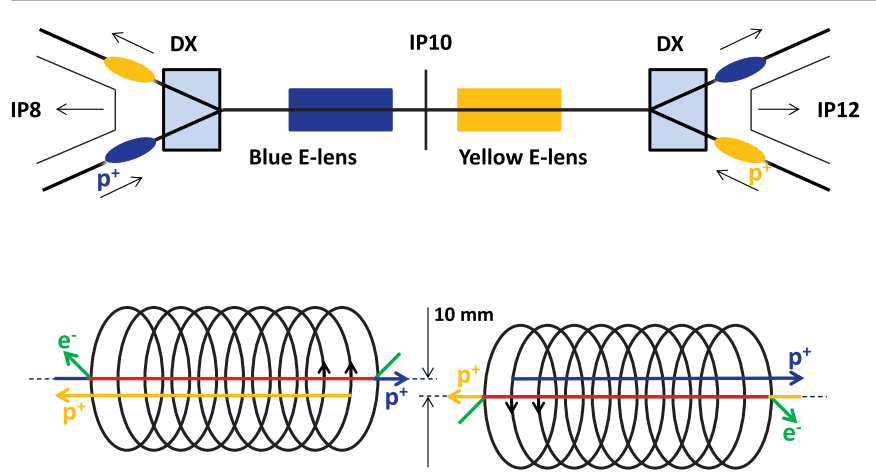

FIG. 2. Schematic not-to-scale illustration of the two $e$-lens locations. The top figure shows the plan view, while the bottom figure shows the side view, which indicates the vertical offset between the blue (left) and yellow (right) $e$-lenses.

In the RHIC, the two electron lenses are located near interaction point IP10 (Fig. 1) between the beam separation dipoles (Fig. 2, top). The RHIC has two rings ("blue" and "yellow"), and counterrotating proton beams collide at the two interaction points IP6 and IP8. Both the blue and the yellow proton beams pass through the superconducting solenoids of both electron lenses. The two superconducting solenoid fields have opposite polarity and therefore locally compensate each other for linear coupling and spin effects. The two superconducting solenoids have vertical offsets (blue, $+5 \mathrm{~mm}$; yellow, $-5 \mathrm{~mm}$ ), while each electron beam propagates through the center of its associated superconducting solenoid and collides head-on with the appropriate proton beam (Fig. 2, bottom).

A list of RHIC electron lens parameters including the proton beam and the electron beam for the $2015100 \mathrm{GeV}$ proton run and for the nominal $250 \mathrm{GeV}$ proton beam are given in Table I.

The theory of the head-on beam-beam compensation has been addressed in several references [3,7-10]. According to these theories, to minimize the beam-beam resonancedriving terms during compensation, the phase advance between the center of the $e$-lenses (not IP10) and IP8 was designed as $k \pi$ ( $k$ is an integer). To reduce the beam-beaminduced tune spread, the electron beam size was designed to have the same transverse size as the proton beam. And the number of protons equals $N_{e}\left(1+\beta_{e}\right)$, where $N_{e}$ is the electron number encountered by a proton in the $e$-lens. Other requirements for the RHIC electron lens system have been presented in Ref. [3].

The lattice design and measurement, the head-on beambeam-induced resonance-driving terms, and tune spread compensation will be presented in another paper [18]. In this paper, the design considerations of the RHIC $e$-lenses needed to satisfy these requirements are presented as well as $e$-lens commissioning results.

The paper is organized as follows. In Sec. II, we give an introduction to the RHIC electron lens system and the characteristics of the electron beam, such as the transverse
TABLE I. The parameters for the RHIC electron lenses.

\begin{tabular}{|c|c|c|c|}
\hline Parameter & Unit & Value & Value \\
\hline Proton beam parameters & & Design & $\begin{array}{l}2015 \\
\text { operated }\end{array}$ \\
\hline \multirow{6}{*}{$\begin{array}{l}\text { Total proton energy } E_{\mathrm{p}} \\
\text { Relativistic factor } \gamma_{\mathrm{p}} \\
\text { Bunch intensity } N_{\mathrm{p}} \\
\beta^{*}{ }_{\mathrm{x}, \mathrm{y}} \text { at IP6, IP8 }(\mathrm{p}-\mathrm{p}) \\
\beta_{\mathrm{x}, \mathrm{y}}^{*} \text { at IP10 }(\mathrm{p}-\mathrm{e}) \\
\text { Lattice tunes }\left(Q_{\mathrm{x}}, Q_{\mathrm{y}}\right)\end{array}$} & $\mathrm{GeV}$ & 250 & 100 \\
\hline & & 266.4 & 106.8 \\
\hline & $10^{11}$ & 3.0 & 2.25 \\
\hline & $\mathrm{m}$ & 0.5 & 0.85 \\
\hline & $\mathrm{m}$ & 10.0 & 15.0 \\
\hline & & $\begin{array}{c}(0.695, \\
0.685)\end{array}$ & $\begin{array}{c}(0.695, \\
0.685)\end{array}$ \\
\hline \multirow{8}{*}{$\begin{array}{l}\text { Phase advance (IP8-IP10) } \\
\text { rms emittance } \varepsilon_{\mathrm{n}} \text {, initial } \\
\text { rms beam size at IP6, IP8, } \sigma^{*}{ }_{\mathrm{p}} \\
\mathrm{rms} \text { beam size at IP10, } \sigma_{\mathrm{p}}^{*} \\
\mathrm{rms} \text { bunch length } \sigma_{\mathrm{s}} \\
\text { Beam-beam parameter } \xi / \mathrm{IP} \\
\text { Number of beam-beam IPs } \\
\text { Electron lens parameters }\end{array}$} & Degree & 180 & 180 \\
\hline & $\mathrm{mm} \mathrm{mrad}$ & 2.5 & 2.8 \\
\hline & $\mu \mathrm{m}$ & 70 & 150 \\
\hline & $\mu \mathrm{m}$ & 310 & 630 \\
\hline & $\mathrm{m}$ & 0.50 & 0.70 \\
\hline & & 0.0147 & 0.0097 \\
\hline & & $2+1$ & $2+1$ \\
\hline & & & \\
\hline Distance of center from IP & $\mathrm{m}$ & 1.5 & 1.5 \\
\hline Effective length $L_{\mathrm{e}}$ & $\mathrm{m}$ & 2.1 & 2.1 \\
\hline Kinetic energy $E_{\mathrm{e}}$ & $\mathrm{kV}$ & 5 & 5 \\
\hline Relativistic factor $\beta_{\mathrm{e}}$ & & 0.14 & 0.14 \\
\hline Relativistic factor $\gamma_{\mathrm{e}}$ & & 1.0002 & 1.0002 \\
\hline Current $I_{\mathrm{e}}$ & A & 1.0 & $0.43 / 0.60$ \\
\hline $\begin{array}{l}\text { Electron beam size at } \\
\text { interaction }\end{array}$ & $\mu \mathrm{m}$ & 350 & 650 \\
\hline Linear tune shift & & 0.0147 & 0.01 \\
\hline
\end{tabular}

density profile, current, energy, beam size, and beam angle control. In Sec. III, we present results from the commissioning and operation of the RHIC electron lenses. Results from a dedicated head-on beam-beam experiment will be presented in Sec. IV. Section V provides information on machine protection and reliability. A summary about all demonstrated requirements is given in Sec. VI.

\section{RHIC ELECTRON LENS SYSTEMS AND CHARACTERISTICS OF THE ELECTRON BEAM}

Figure 3 is a schematic horizontal sectional view of one RHIC electron lens. Each RHIC electron lens includes an electron gun and collector [19], magnets [20,21], instrumentation [22], drift tubes, vacuum pipes, and high-voltage power supplies. The electron beam trajectory is shown in Fig. 3 as a dashed line.

To achieve successful operation of the electron lenses, according to the simulation [3] as well as the Tevatron experience [23], a smooth transverse distribution of the electron current density is required. An electron beam with a Gaussian transverse profile was designed for the RHIC $e$-lenses which has the same transverse distribution as the RHIC proton beam.

In addition, the electron beam should have a high current to compensate up to $3.0 \times 10^{11}$ protons per bunch, a variable 


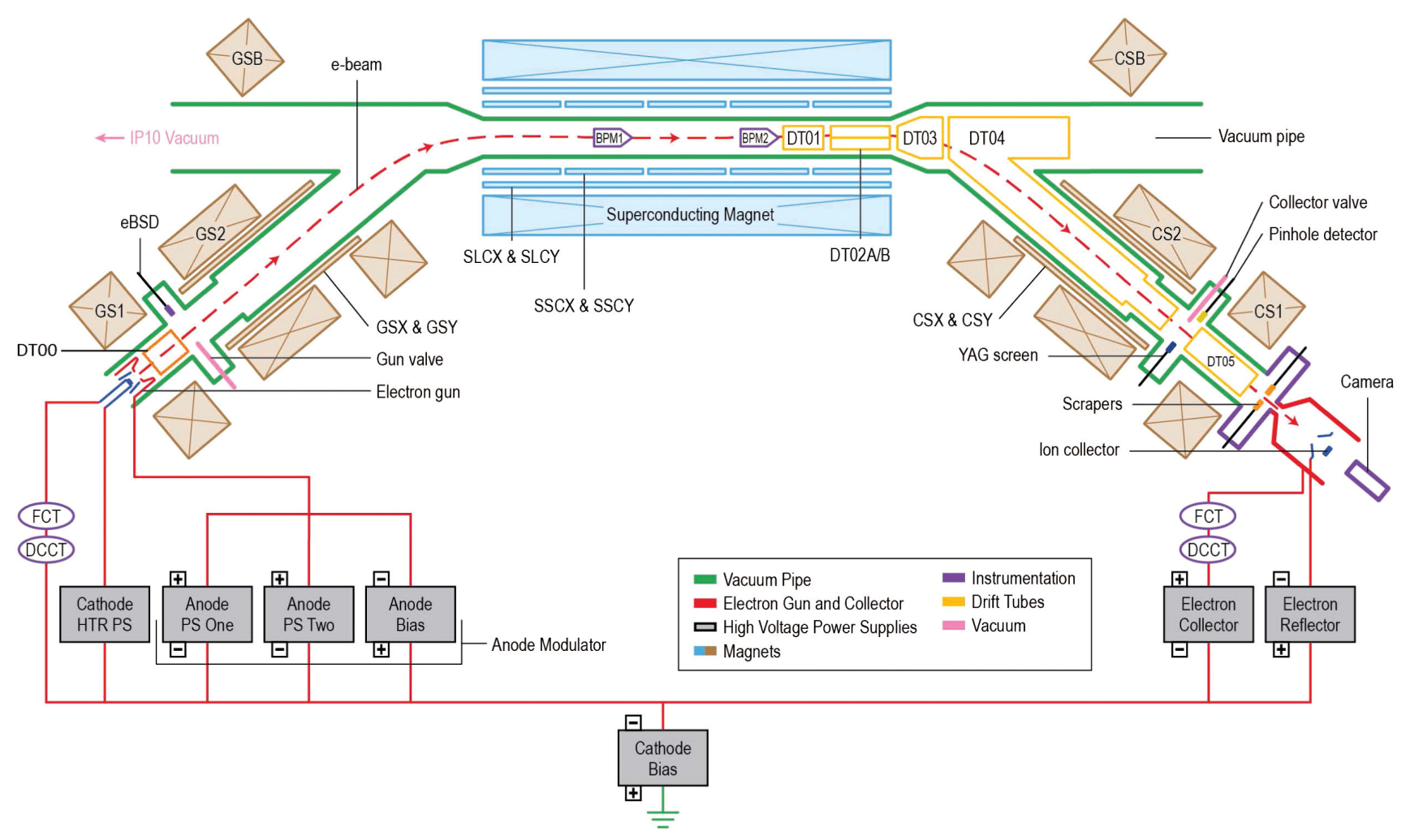

FIG. 3. Schematic layout of the RHIC electron lens.

electron beam size to match the proton beam size, and a good alignment of the electron beam on the beam of interest.

In the following section, the individual systems and their design consideration are discussed, and some electron beam characteristics are presented.

\section{A. Cathode size and material}

To satisfy a $1.0 \mathrm{~A}$ dc electron beam current requirement, an emission current density on the cathode surface of $10 \mathrm{~A} / \mathrm{cm}^{2}$ is needed [18]. The choice for this electron source is a hightemperature thermionic cathode electron gun.

For head-on beam-beam compensation with $250 \mathrm{GeV}$ proton beams, $\mathrm{IrCe}$ (iridium-cerium alloy) is selected as the $4.1 \mathrm{~mm}$ radius cathode material [18]. IrCe offers a comfortable combination of a high-emission current density and a long lifetime. $\mathrm{A} \mathrm{LaB}_{6}$ (monocrystalline lanthanum hexaboride) cathode was also tested on the RHIC electron lens test bench [24]. These cathodes were manufactured by the Budker Institute of Nuclear Physics and have an expected lifetime of more than $20000 \mathrm{~h}$ under nominal operating conditions $[25,26]$.

In order to match a proton beam size that is larger at $100 \mathrm{GeV}$ than at $250 \mathrm{GeV}$, a cathode with a $7.5 \mathrm{~mm}$ radius was installed and used during the 2015 RHIC run [27,28]. This cathode was a dispenser cathode (porous tungsten matrix impregnated with a barium-based emission-enhancing material). The cathode was powered with an ac power supply instead of a dc power supply and had to be activated properly according to a detailed procedure to avoid potential poisoning through contamination with particles [27].

\section{B. Beam profile and electron gun design}

To get the required beam transverse profile, the designed electron gun uses a control electrode in addition to the cathode and anode-similar to the Fermilab gun design [10]. But to meet the required Gaussian emission profile, the initial spherical cathode surface was modified as well as the geometries of the control electrode and the anode.

The simulation of the electron gun was done with the 2D package Tricomp from Field Precision [29]. As is shown in Fig. 4 (left plot), after multiple iterations, the geometry and dimension of the control electrode, the anode, and the shape of the cathode are designed to achieve a Gaussian emission current density profile with small deviations.

During the above iterations, the distances between these elements were optimized, which is shown in the right plot in Fig. 4. The quality criterion of these parameters, as well as the cathode surface shaping, is an error parameter defined as

$$
\mathrm{ER}=\frac{\sum_{1}^{\mathrm{n}}\left(\mathrm{i}_{\text {Gauss }}-\mathrm{i}_{\text {Sim }}\right)^{2}}{\mathrm{n} \cdot \mathrm{A}},
$$

where $i_{\text {Sim }}$ is the emission current density at the surface of the cathode for one simulated particle trajectory; $\mathrm{i}_{\text {Gauss }}$ is the Gaussian fit of emission current density for the radius of the same particle trajectory; $\mathrm{n}$ is the total number of 

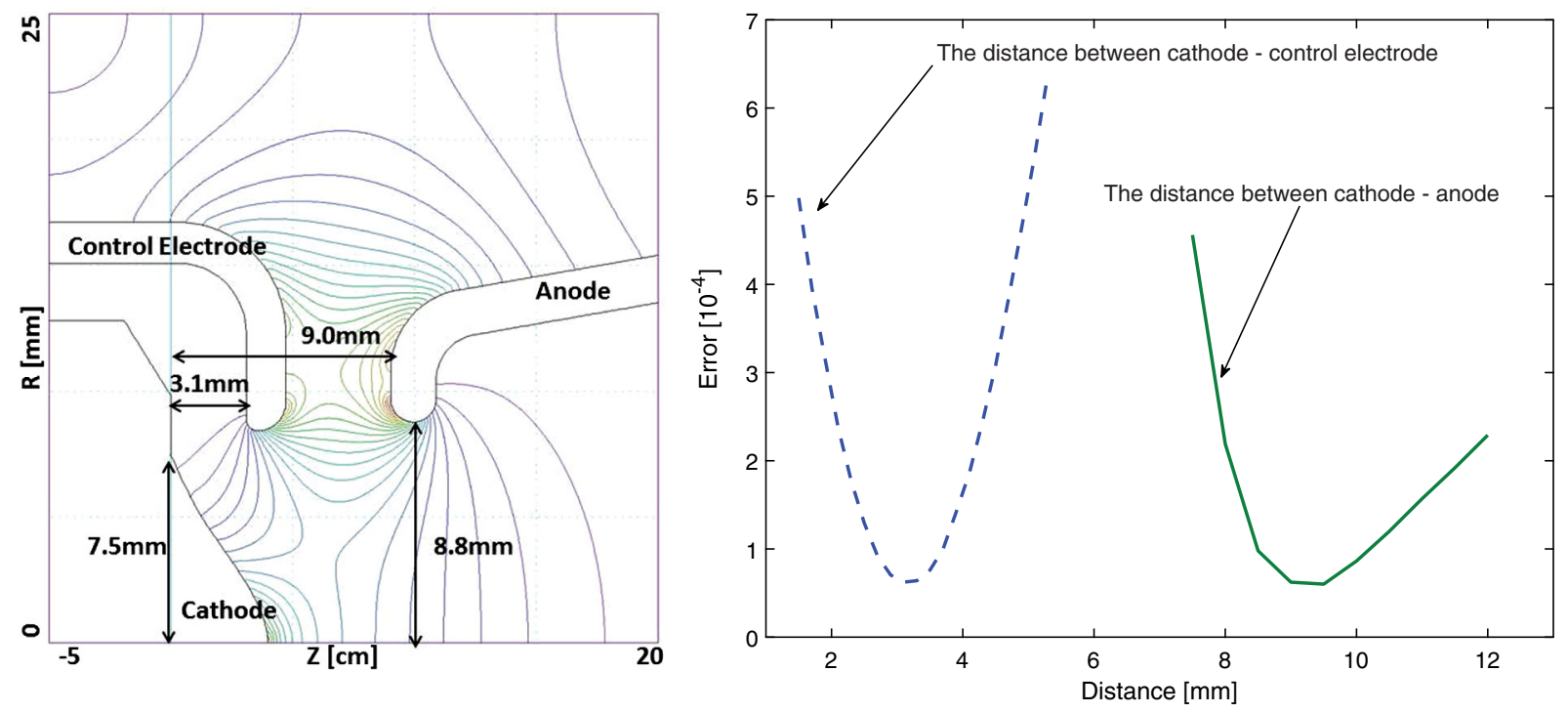

FIG. 4. Electron gun design and optimization.

trajectories from the simulation; and A is the amplitude of the fitted Gaussian profile.

The optimization of the cathode surface and other dimensions was done manually. In this process, the coordinates of the cathode surface were optimized for each radius, and the mismatch between the simulated and Gaussian distributions is just a result of this process.

In addition to the cathode design, the manufacturing quality of the cathode is another ingredient to ensure the transverse Gaussian beam profile. Therefore, after the cathodes were manufactured, their surface curves were measured via the optical comparator method and inspected using an optical go-no go gauge. Then, these measured cathode profiles were used as inputs to simulate the electron beam profile from these cathodes. Several of the best cathodes were chosen based on the simulation results. All the above-mentioned procedures ensure that the beam profile is as close as possible to a Gaussian profile.

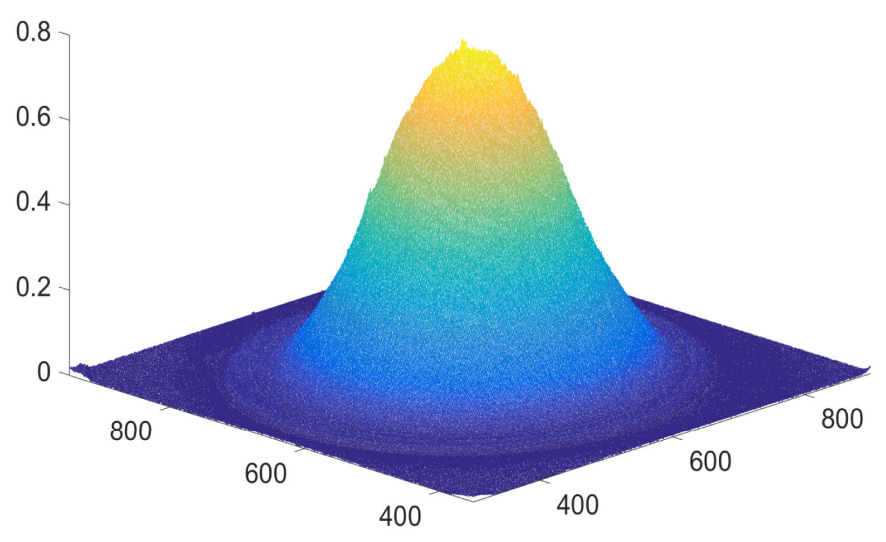

Figure 5 shows electron beam profiles and their Gaussian fits for the IrCe cathode and the tungsten dispenser cathode, measured using a YAG screen near the $e$-lens collector. The residuals as a function of the radial coordinate are also shown at the right bottom plot in Fig. 5. It was demonstrated that the measured profiles were fitted to Gaussian distributions very well. The measured cathode radius to rms beam size ratio $\mathrm{r} / \sigma$ was 2.8 for the $\mathrm{IrCe}$ and 2.7 for the tungsten cathode, while the design value was 2.8 .

\section{Beam current and electron gun perveance}

For the beam-beam compensation, the required current in the electron lens is [3]

$$
\mathrm{I}_{\mathrm{e}}=\frac{\mathrm{eN}_{\mathrm{p}} \beta_{\mathrm{e}} \mathrm{c}}{\left(1+\beta_{\mathrm{e}}\right) \mathrm{L}_{\mathrm{e}}}
$$

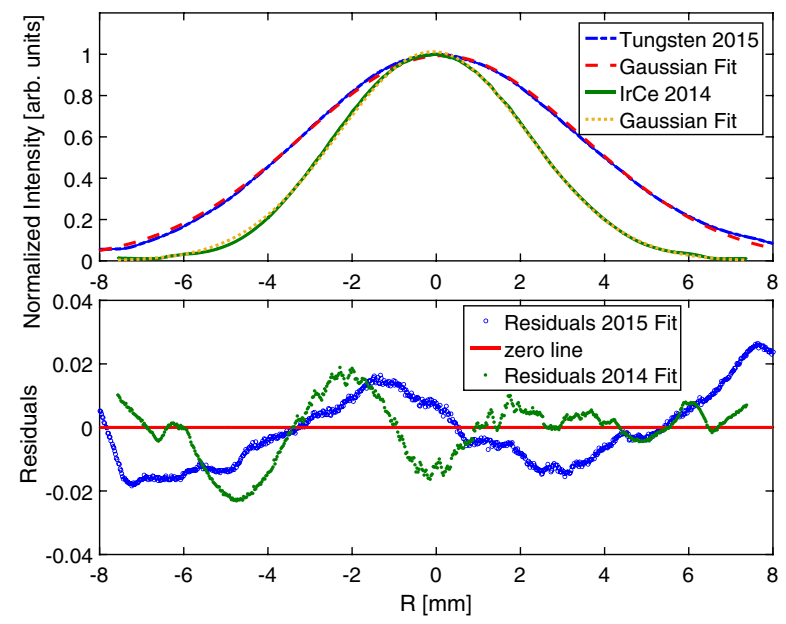

FIG. 5. Transverse beam profile measurement. 
where $N_{p}$ is the number of protons encountered by a electron in the electron lens; $L_{e}$ is the effective length of the electron lens; and $\beta_{\mathrm{e}} \mathrm{c}$ is the speed of the electrons. The required electron beam current for an $N_{p}=3 \times 10^{11}$ proton beam is $1 \mathrm{~A}$ for $5 \mathrm{keV}$ electron kinetic energy.

For an electron gun operating at the space charge limit, the gun perveance is a key parameter. It gives the current for a certain anode voltage expressed by Child's law [30-33]

$$
\mathrm{I}_{\mathrm{e}}=\mathrm{P}_{\text {gun }} \cdot \mathrm{U}_{\text {anode }}^{3 / 2},
$$

where $\mathrm{P}_{\text {gun }}$ is the gun perveance determined by the geometry of the electron gun for a specific cathode material and $\mathrm{U}_{\text {anode }}$ is the anode potential difference with respect to the cathode.

The perveances of the $7.5 \mathrm{~mm}$ cathode radius electron lens electron guns were measured and shown in Fig. 6. They are 2.7 and $2.55 \mu \mathrm{AV}^{-3 / 2}$ for the blue and yellow electron guns, respectively, with a pulsed beam. With these perveances, the $1 \mathrm{~A}$ design dc electron beam current was demonstrated.

During the commissioning and operation, the current and voltage of the cathode filament heater for the $4.1 \mathrm{~mm}$ radius IrCe cathode were $10 \mathrm{~A}$ and $9.3 \mathrm{~V}$, respectively, while for the $7.5 \mathrm{~mm}$ radius tungsten cathode they were $2.7 \mathrm{~A}$ and $14 \mathrm{~V}$, respectively.

\section{Electron beam propagation and solenoids}

As shown in Fig. 3, after the electron beam is emitted from the electron gun, which is immersed in the gun side solenoid 1 (GS1) magnetic field, it is propagated towards the interaction region inside the superconducting magnet, by means of the conventional warm solenoids GS2 and GSB.

After the interaction region, the electron beam passes through CSB and the collector side solenoids CS2 and CS1 and is finally absorbed by a collector. The dashed line with

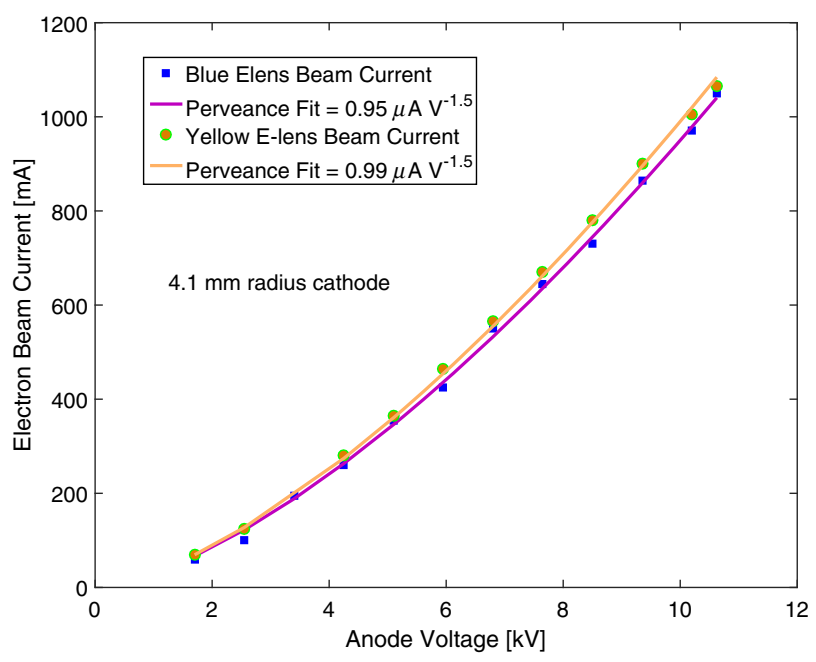

arrow in Fig. 3 indicates the electron beam trajectory. For the $5 \mathrm{keV}$ low-energy electron beam in the RHIC electron lens, the electron beam closely follows the magnetic field lines, with small distortions due to the $\vec{E} \times \vec{B}$ drift from self-fields and $\vec{B} \times \nabla \vec{B}$ in the toroidal bends.

The combined fields of the GSB and the superconducting magnet dominate the horizontal electron beam position. Four correctors, the gun side horizontal corrector (GSX), gun side vertical corrector (GSY), collector side horizontal corrector (CSX), and collector side vertical corrector (CSY), are used for the beam position adjustment.

To avoid unwanted transverse profile distortion [34] and electron beam instabilities, the minimum magnetic field from the electron gun to the interaction region was designed to be $\geq 0.3 \mathrm{~T}$.

In order to control the electron beam size and position inside the superconducting magnet without affecting the beam trajectory, GS1 is placed away from the entrance of the superconducting magnet. GS2 provides a $\geq 0.3 \mathrm{~T}$ magnetic field between GS1 and GSB, as well as longitudinal space for the GSX and GSY dipole correctors, which are mounted inside GS2.

The power supply connections for the two electron lenses, the magnetic field, the electron beam, and the proton beam direction are shown in Fig. 7. To reduce the number of power supplies, for each ring (blue or yellow), the GSB and CSB magnets share the same power supply, as well as the GS2 and CS2 magnets. The blue GS1 and yellow GS1 share one power supply, as well as the blue CS1 and yellow CS1. Therefore, the beam size before the collector entrance can be controlled independently from the gun side [19].

\section{E. Superconducting magnet and correctors}

A strong magnetic field in the interaction region is needed to stabilize the low-energy electron beam during the

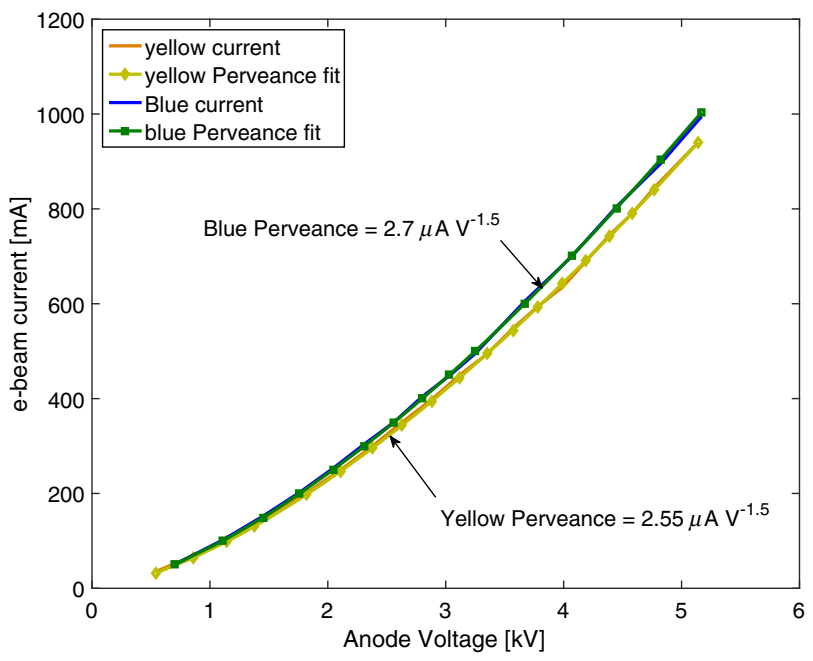

FIG. 6. Electron gun perveance for the $4.1 \mathrm{~mm}$ radius cathode (left) and $7.5 \mathrm{~mm}$ radius cathode (right). 


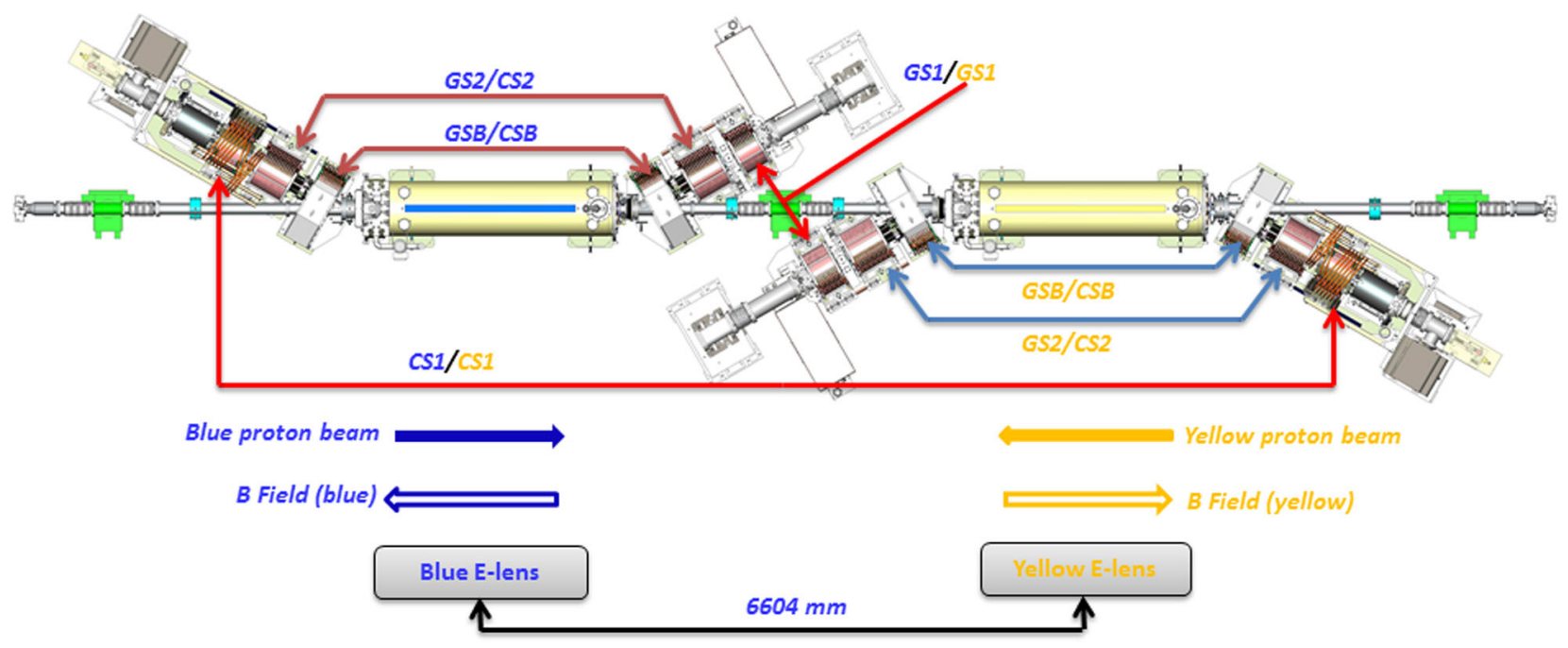

FIG. 7. Schematic layout of the two RHIC $e$-lenses and shared warm solenoid power supply connection.

interaction with the proton beam [10]. The up to $6 \mathrm{~T}$ strong field is also used to magnetically compress the electron beam to the proton beam size [18].

Figure 8 shows the cross section of the superconducting magnet, which includes the main coil, trim coil, fringe coil, antifringe coil, and a total of 12 dipole correctors. The ends of the main coil have an additional four layers wound in the "trim" area as a trim coil, for better field quality and better force distribution inside the conductor. The main coil and trim coil use the same conductor; therefore, they are energized with the same power supply to provide the $6 \mathrm{~T}$ magnetic field. The fringe coil was designed to maintain the minimum $0.3 \mathrm{~T}$ magnetic field between the GSB and the superconducting magnet. It is located outside the shielding yoke.

According to Opera [35] simulations, the effects of the magnetic field on the beam trajectory from the main coil and trim coil can be neglected. The beam position is dominated by the combined fields of the GSB and fringe coil. Therefore, during commissioning and operation, it was convenient to change the main coil magnetic field without retuning the beam trajectory. The antifringe coil was designed and installed to compensate the main coil field distortion because of the fringe coil. However,

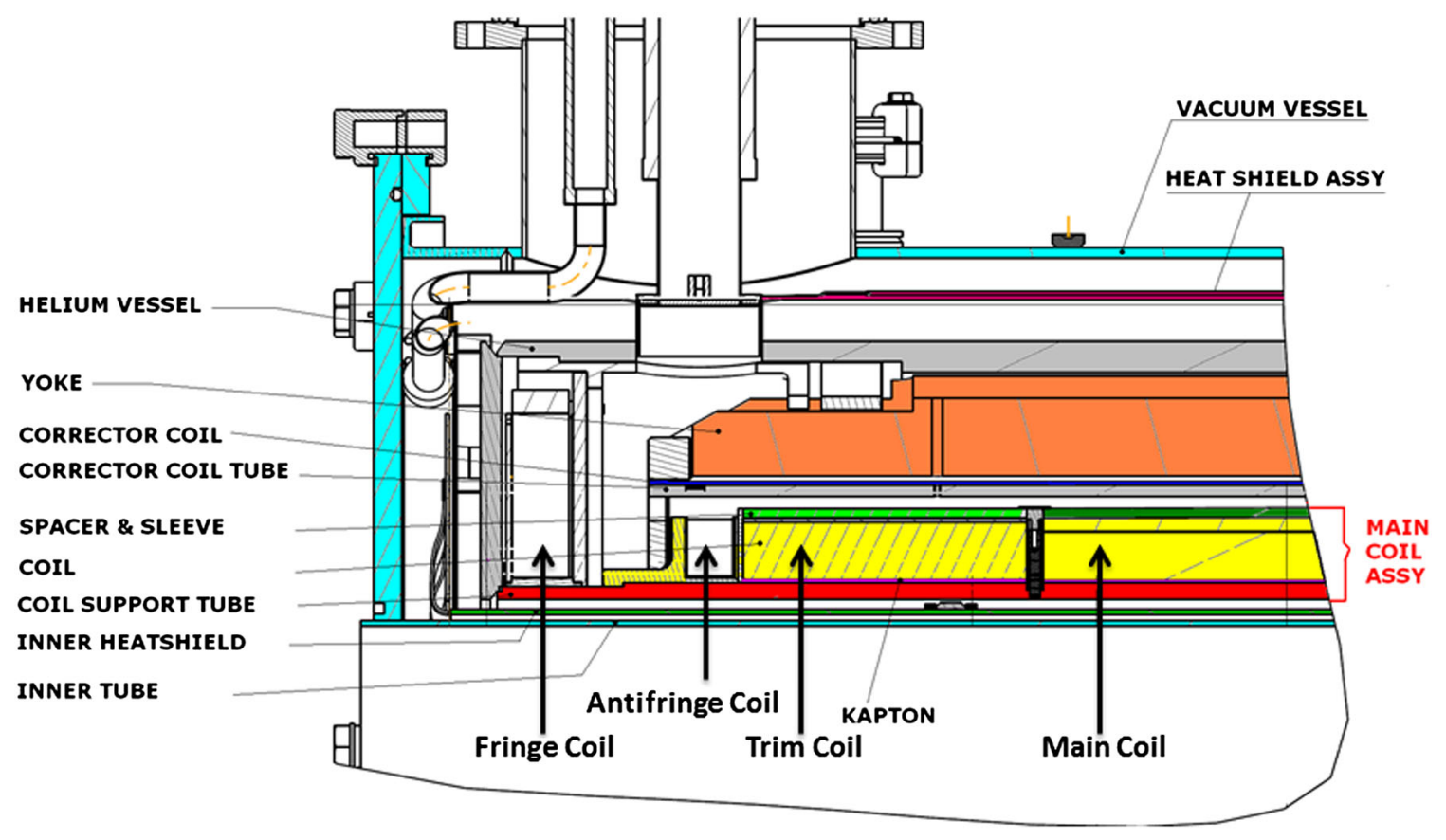

FIG. 8. Cross section of the RHIC electron lens superconducting magnet. 
after magnetic field measurements it was found that the effects of the fringe coil on the main magnetic field are negligible.

In order to prevent the superconducting magnetic field straightness from being affected by the magnetic field outside, a layer of shielding yoke was added to the design. Thus, we established small magnetic field leakage and a greater length with good field quality.

The field lines in the superconducting magnet should not deviate from a straight line by more than $10 \%$ of an rms beam size [3]. Therefore, five horizontal and five vertical short correctors (SSCX and SSCY) were included for straightness correction. The design also includes one horizontal and one vertical long corrector (SLCX and SLCY), to control the electron beam angle inside the superconducting magnet. All dipole correctors are superconducting in the same cryostat and wired in the same corrector coil tube slot [20], which is located outside the superconducting solenoid.

When we measured the superconducting magnetic field straightness [36], we found the magnetic field straightness is sufficient without any correction.

The specifications for the superconducting magnet are listed in Table II. More information can be found in some conference proceedings about the conceptual design [20], mechanical design [37], and vertical test [38]. The power supplies are described in Ref. [39].

TABLE II. Parameters for the RHIC electron lens superconducting solenoid.

\begin{tabular}{lcc}
\hline \hline Parameters & Unit & Value \\
\hline Effective compensation length & $\mathrm{m}$ & 2.1 \\
Maximum field & $\mathrm{T}$ & 6 \\
Operated field & $\mathrm{T}$ & $1.5-6$ \\
Designed current & $\mathrm{A}$ & 470 A (blue), \\
& & 424 A (yellow) \\
Number of main coil layers & & 20 (blue), \\
& $\mathrm{mm}$ & 22 (yellow) \\
Inner diameter & $\mathrm{mm}$ & 200 \\
Outer diameter & $\mathrm{mm}$ & 274 \\
Coil length (main and trim) & $\mathrm{mm}$ & 2360 \\
Yoke length & $\mathrm{mm}$ & 2810 \\
Total cryostat length & & 2 (horizontal \\
Long correctors number & & and vertical) \\
& $\mathrm{mT}$ & 6 \\
Long correctors field & $\mathrm{m}$ & 2.5 \\
Long correctors length & $\mathrm{mrad}$ & 2 (3 T main field) \\
Beam angle changed by & & \\
$\quad$ long corrector & & 10 (horizontal \\
Short correctors number & & and vertical) \\
& & 20 \\
Short correctors field & $\mathrm{mT}$ & 0.5 \\
Short correctors length & $\mathrm{m}$ & 6.7 (3 T main field) \\
Beam angle changed by & $\mathrm{mrad}$ & \\
$\quad$ short correctors & & \\
\hline \hline & & \\
\hline
\end{tabular}

\section{F. Beam overlap and field quality measurement}

Optimal overlap of the electron and proton beam is essential for the head-on beam-beam compensation [3].

The trajectory of spiraling low-energy electrons $(\sim 5 \mathrm{keV})$ follows the field lines in the interaction region. Any deviation of the magnetic field from a straight line will cause the electron trajectories to deviate from the straight proton beam trajectory by the same value. The effect of such an offset was studied with simulations and reported in Ref. [3]. According to the simulations for $250 \mathrm{GeV}$ protons, the beam lifetime is tolerable in the offset range up to $30 \mu \mathrm{m}$. This tolerance was later relaxed to $50 \mu \mathrm{m}$, because $30 \mu \mathrm{m}$ were difficult to achieve by any manufacturer. For the $100 \mathrm{GeV}$ proton beam, the tolerance could be further relaxed to $80 \mu \mathrm{m}$ due to the larger beam size at this energy.

The straightness of the magnetic field in the superconducting solenoid was measured with the same technique as was used for the Tevatron electron lens [10], and the results are shown in Fig. 9 for a $4 \mathrm{~T}$ main coil field. For the blue magnet horizontal plane, the deviation falls between $\pm 50 \mu \mathrm{m}$ from -1200 to $1000 \mathrm{~mm}$. For the blue magnet vertical plane and yellow magnets, the deviations are less than $\pm 50 \mu \mathrm{m}$ inside a $\pm 850 \mathrm{~mm}$ range and less than $\pm 100 \mu \mathrm{m}$ within a $\pm 1000 \mathrm{~mm}$ range. During the field measurement it was found that the warm solenoids (GSB) do not affect the straightness of the field. Similar field straightness measurements for 2 and $3 \mathrm{~T}$ magnetic fields were also performed with similar results.

\section{G. Beam size and solenoid field}

For operational beam-beam compensation, the electron beam size should be 1.2-1.4 times the proton beam size [3]. The transverse rms size of the electron beam in the interaction region is given by

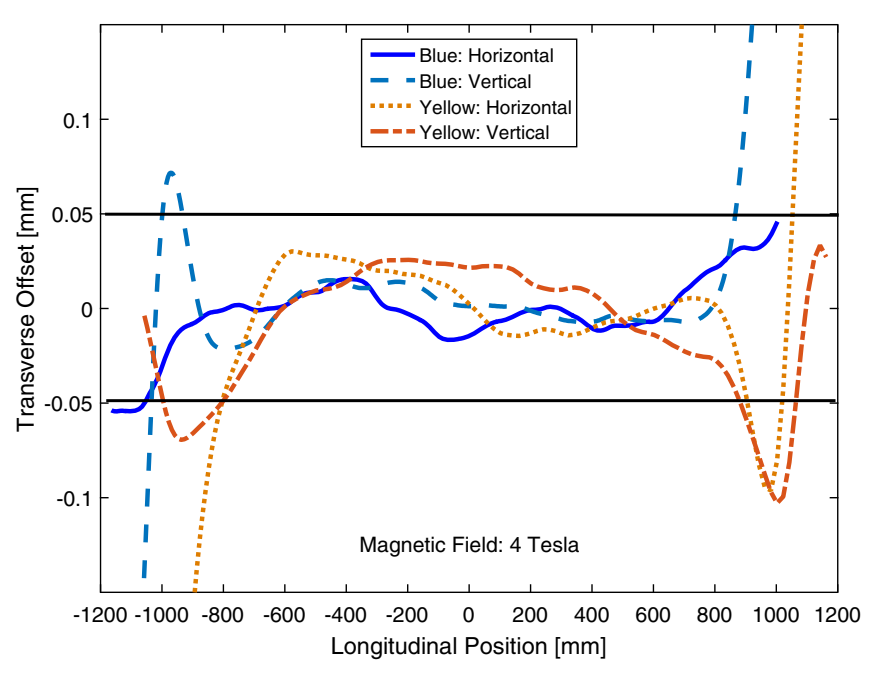

FIG. 9. Field straightness measurements of the main superconducting magnet. 


$$
\sigma_{\text {center }}=\sigma_{\text {cathode }} \sqrt{\frac{\mathrm{B}_{\text {cathode }}}{\mathrm{B}_{\text {center }}}},
$$

where $\sigma_{\text {center }}$ and $\sigma_{\text {cathode }}$ are the rms sizes of the Gaussian distribution in the superconducting solenoid (interaction region) and at the cathode, respectively, while $\mathrm{B}_{\text {center }}$ and $\mathrm{B}_{\text {cathode }}$ are the magnetic fields in the superconducting solenoid and at the cathode, respectively.

The magnetic fields at the cathode and the interaction region were measured. However, there was no field measurement made at the YAG screen where the beam profile is obtained. Instead, the rms beam size $\sigma_{\text {cathode }}$ on the cathode surface is calculated from the $\mathrm{r} / \sigma$ ratio, which was measured on the YAG screen. After that, the electron beam size at the interaction region is calculated from the magnetic field ratio between the interaction region and the cathode.

Here it was assumed that the beam profile distortion between the cathode and the YAG screen is negligible [34]. Therefore, the $\mathrm{r} / \sigma$ ratio, which is measured on the YAG screen, can be used on the cathode side to calculate the beam size with a known cathode radius $r$.

The specifications for the cathode and the electron beam size are listed in Table III. The minimum gun magnetic field $\mathrm{B}_{\text {cathode }}$ achieved in the yellow electron lens was $0.07 \mathrm{~T}$ with $\mathrm{B}_{\text {center }}=4.92 \mathrm{~T}$ for $500 \mathrm{~mA}$. During the test, the $7.5 \mathrm{~mm}$ radius cathode was used, and the electron beam energy was $5 \mathrm{keV}$. According to Table III, adjusting the electron beam size appropriately can accommodate a wide range of proton beam sizes.

Electron beam position variations were dominated by a current ripple of the GSB, the fringe and the main coil, and the warm correctors. Their power supplies have a current ripple specification of $10^{-4}$. With this specification, the electron beam position jitter was calculated to be $3 \mu \mathrm{m}$, which is less than the design requirement of $9 \mu \mathrm{m}$ [3] for $250 \mathrm{GeV}$ proton beams. For this calculation, the transfer functions between the magnet current and beam position were obtained with Opera [35] simulations.

\section{H. Beam energy and potential control}

The electron beam energy is not only a parameter in the head-on beam-beam tune shift calculation, it is also a factor in the electron beam propagation. The electron beam energy is controlled by the electron lens potential control system shown in Fig. 3.

The vacuum pipe and drift tube are at the ground potential. The cathode is connected to the cathode bias power supply $(6 \mathrm{kV})$, and the cathode bias platform potential $(-6 \mathrm{kV})$ is below the ground potential.

The anode modulator power supplies (anode power supply one and two, Fig. 3, 0-12 kV), cathode heater, and collector power supplies $(4 \mathrm{kV})$ are on the cathode bias platform with a potential above the cathode bias. At the same time, the reflector power supply $(3 \mathrm{kV})$ forms a potential $(-9 \mathrm{kV})$ below the cathode bias. This configuration brings the reflector potential further below the cathode potential to reflect the electron beam back to the collector.

The collector potential $(-2 \mathrm{kV})$ is nominally above the cathode bias potential and below the ground potential. While the YAG screen or pinhole was used for the electron beam profile measurement, the collector potential $(1 \mathrm{kV})$ was set above the ground potential. This was to prevent the secondary electrons emitted by the YAG screen or pinhole from going back to the cathode. All bipolar drift tube power supplies are at the ground potential and can be controlled individually.

The nominal anode potential is from -6 to $6 \mathrm{kV}$ with cathode platform potential $-6 \mathrm{kV}$ and anode voltage from 0 to $12 \mathrm{kV}$. When no beam is needed, the anode potential is kept as $-6.5 \mathrm{kV}$ by switching the anode from the anode power one and two (Fig. 3) to the anode bias power supply $(0.5 \mathrm{kV})$. The anode bias power supply negative terminal is connected to the cathode bias platform (see Fig. 3).

With the above configuration, the electron beam energy can be controlled by the cathode bias voltage, and the electron beam power on the collector is controlled by the collector voltage.

TABLE III. Parameters for the electron gun design.

\begin{tabular}{|c|c|c|c|}
\hline Proton energy $[\mathrm{GeV}]$ & 100 & & 250 \\
\hline Cathode material & Tungsten & & $\mathrm{IrCe}$ \\
\hline Cathode radius $[\mathrm{mm}]$ & 7.5 & & 4.1 \\
\hline Measured $\mathrm{r} / \sigma$ Ratio & 2.7 & & 2.8 \\
\hline$E$-beam size (cathode) $[\mathrm{mm}]$ & 2.78 & & 1.46 \\
\hline Designed gun field $[\mathrm{T}]$ & & $0.2 \leq \mathrm{B}_{\text {cathode }} \leq 0.8$ & \\
\hline Superconducting field $[\mathrm{T}]$ & & $2.0 \leq \mathrm{B}_{\text {center }} \leq 6.0$ & \\
\hline$E$-beam size compression ratio & & $1.6 \leq \mathrm{C}_{\text {ratio }} \leq 5.5$ & \\
\hline$E$-beam size $[\mathrm{mm}]$ & $0.5 \leq \sigma_{\text {center }} \leq 1.74$ & & $0.27 \leq \sigma_{\text {center }} \leq 0.92$ \\
\hline Achieved min. $E$-beam size $[\mathrm{mm}]$ & 0.35 & & $\cdots$ \\
\hline Proton emittance [mm mrad] & 2.5 & & 2.5 \\
\hline Proton beam size $[\mathrm{mm}]$ & 0.48 & & 0.31 \\
\hline $1.2-1.4^{*}$ proton beam size $[\mathrm{mm}]$ & $0.58-0.67$ & & $0.37-0.43$ \\
\hline
\end{tabular}




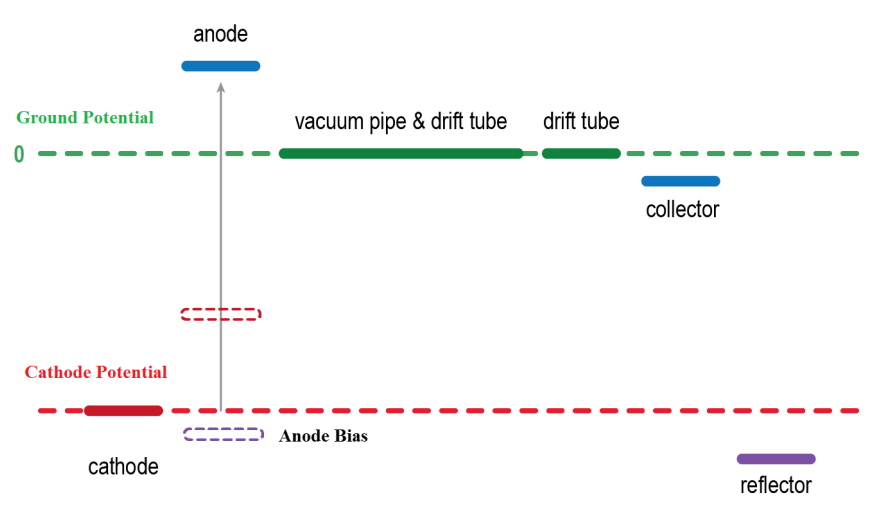

FIG. 10. Diagram of the RHIC $e$-lens potentials.

Figure 10 shows the configuration of potentials for different components of the RHIC $e$-lenses used to control the electron beam energy. Table IV shows the design highvoltage power supply parameters and the potential for each component as well as the electron beam energy.

As mentioned previously, without an electron beam, the anode potential should be kept below the cathode potential with the anode bias power supply. If the anode is floating without the negative connection, the divided voltage on the anode from the modulator [24] could result in a dark dc electron beam current from the cathode. The dark dc current could result in YAG screen damage and unwanted beam-beam interaction during ion beam injection.

As part of the $e$-lens test bench [24], the gun dark current was measured as a function of the gun solenoid current and is shown in Fig. 11. For the installed RHIC electron lenses, the modulator has been improved, and the resulting induced dc current could be kept below $15 \mathrm{~mA}$. After switching to the anode bias, the anode potential $(-6.5 \mathrm{kV})$ is lower than the cathode potential $(-6 \mathrm{kV})$; therefore, the dark current has been eliminated.

\section{Beam propagation and drift space perveance}

As discussed in the previous section, the electron gun perveance, which is a property of the electron gun, is used to define how many electrons the anode can draw from the cathode. After the electrons leave the cathode and start propagating in the drift space, the drift space perveance can be used to determine the minimum cathode bias voltage required to overcome the space charge effect and propagate the beam through a drift space.

For a nonrelativistic low-energy beam propagating through a drift tube or vacuum chamber, it is assumed that the beam is accelerated in a stationary electric field. In this case, the drift space perveance can be written as [33]

$$
\mathrm{P}_{\text {drift non }}=\mathrm{I}_{\mathrm{e}} / \mathrm{U}_{\text {drift }}^{3 / 2} \text {, }
$$

where $I_{e}$ is the maximum current that can propagate through the drift tube, $\mathrm{U}_{\text {drift }}$ is the beam energy which equals to $U_{c}-U(r), U_{c}$ is the potential difference between the cathode and drift tube (or cathode bias power supply voltage), and $U(r)$ is the space charge potential from the electron beam itself. For a uniform density beam, the peak potential from space charge on beam axis can be written as

$$
\mathrm{U}_{\mathrm{r}=0}=\frac{I_{e}}{4 \pi \epsilon_{0} \beta_{e} c} \cdot\left(1+2 \ln \frac{b}{a}\right),
$$

where $\mathrm{b}$ is the beam pipe radius, $a$ is the beam radius, and $\frac{a}{b}$ is the beam filling factor.

For propagating relativistic beams, the contribution of the space charge appears as a dimensionless parameter called the generalized perveance [40].

The maximum electron beam current has been measured with different beam energies using the RHIC electron lens test bench [24]. During these measurements, the cathode heater current was $10 \mathrm{~A}$, and the beam pulse length was $10 \mu$ s. Any current above the maximum current curve in Fig. 12 will result in a virtual cathode build-up, which is indicated by the waveform of the halo scrapers [24]. For GS1 with $0.31 \mathrm{~T}$, the drift space perveance was found to be $\mathrm{P}_{\text {drift non }}=2.15 \mu \mathrm{AV}^{-1.5}$ after fitting the curve in Fig. 12 . As shown in Fig. 12, the higher gun solenoid field, which means a larger beam size inside the superconducting magnet, leads to less space charge effect and increases the drift perveance. But for the RHIC $e$-lens, the gun solenoid field GS1 is predetermined because of the beam size requirement. Therefore, the cathode bias power supply was used to control the drift space perveance.

\begin{tabular}{|c|c|c|c|c|c|c|}
\hline & & Vacuum & Cathode & Anode & Collector & Reflector \\
\hline \multirow[t]{2}{*}{ No electron Beam } & PS voltage $[\mathrm{kV}]$ & 0 & 6 & 0.5 & 4 & 3 \\
\hline & Potential $[\mathrm{kV}]$ & 0 & -6 & -6.5 & -2 & -9 \\
\hline \multirow[t]{3}{*}{ With electron Beam } & PS voltage $[\mathrm{kV}]$ & 0 & 6 & $0-12$ & 4 & 3 \\
\hline & Potential $[\mathrm{kV}]$ & 0 & -6 & $-6-6$ & -2 & -9 \\
\hline & Beam energy $[\mathrm{keV}]$ & 6 & 0 & $0-12$ & 4 & $\ldots$ \\
\hline \multirow{3}{*}{ Beam for profile measurement } & PS voltage $[\mathrm{kV}]$ & 0 & 4 & $0-12$ & 5 & 3 \\
\hline & Potential $[\mathrm{kV}]$ & 0 & -4 & $-4-8$ & 1 & -9 \\
\hline & Beam energy $[\mathrm{keV}]$ & 4 & 0 & $0-12$ & 5 & $\ldots$ \\
\hline
\end{tabular}

TABLE IV. Parameters for the beam potential and energy control. 


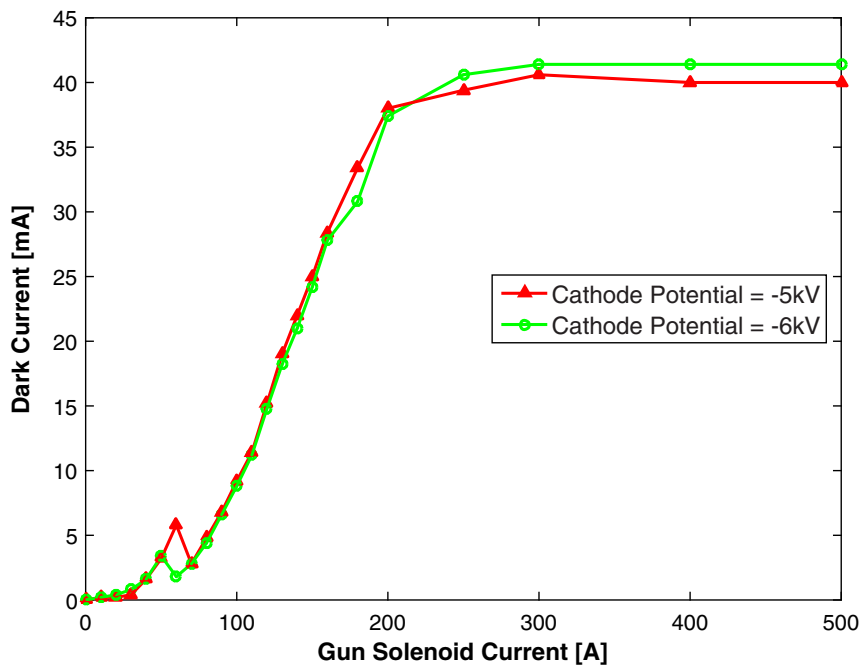

FIG. 11. Electron beam current caused by cathode bias.

To transmit all the electron-beam current that is produced by the electron gun, the minimum required beam energy can be calculated from the perveances of the gun and the drift space. From Eqs. (3) and (5), the minimum energy is

$$
\mathrm{U}_{\text {energy min }}=\left(\frac{\mathrm{P}_{\text {gun }}}{\mathrm{P}_{\text {drift non }}}\right)^{2 / 3} \cdot \mathrm{U}_{\text {anode }} \text {. }
$$

According to the discussion above, although the lower beam energy can provide higher head-on beam-beam compensation [3] and space charge compensation effect [41], there is a minimum energy for a certain current that limits the maximum electron beam current that can propagate in the $e$-lenses.

For the RHIC electron lens, with a $6 \mathrm{kV}$ cathode bias and 1 A electron beam, no space-charge-induced electron beam instability was found. During the 2015 RHIC run, a $5 \mathrm{kV}$ cathode bias was used for the $e$-beam currents below $700 \mathrm{~mA}$.

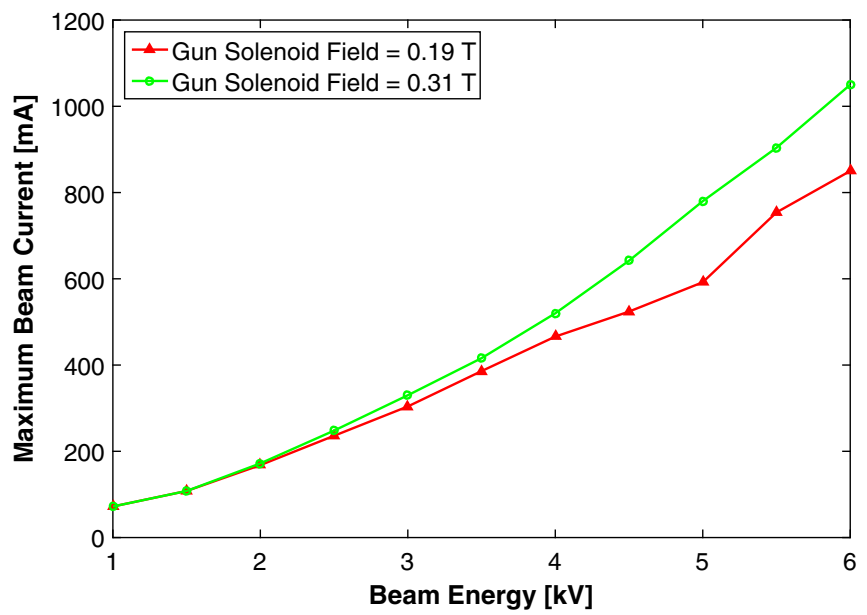

FIG. 12. Measurement of drift space perveance with different GS1 currents.

\section{J. Electron collector}

The RHIC electron lens collector design is based on the Electron Beam Ion Source (EBIS) collector [42], which has a reflector to reflect the electron beam towards the collector inner wall and an open exit in the back for an ion vacuum pump, which can handle a heavy gas load. This open exit also provides the path for electron beam imaging with a CCD camera that can be placed behind the collector (see Fig. 3).

The electron collector must dissipate the power of the electron beam. The nominal current of the electron beam is $1 \mathrm{~A}$, and the maximum is close to $2 \mathrm{~A}$. For a $2 \mathrm{~A}$ electron beam, the maximum temperature on the inner surface of the shell is $102{ }^{\circ} \mathrm{C}$. This temperature is acceptable for the material (copper) and for UHV conditions in the RHIC. Twenty tubes with an inner diameter (ID) of $8 \mathrm{~mm}$ are brazed to the outside of the cylindrical shell and are connected in parallel for water flow. The total power dissipation on the collector can be reduced with a lower collector voltage.

To monitor the dissipated electron beam distribution inside the collector via measuring the collector temperature distribution, eight resistive thermal device type temperature sensors are mounted on the outside surface of the collector. This system provides information about the alignment of the electron beam to the collector.

\section{K. Instrumentation and diagnostics}

Some instrumentation $[21,22]$ is designed for the electron beam parameter measurements, such as the beam current, beam position, and beam profile [24]. Besides the beam parameter measurements, some system statuses should be monitored, such as the anode voltage, the cathode potential, the losses of electron beam current, the collector temperature, the ion current, and drift tube signal. These diagnostics can provide useful information during the commissioning and operation.

The beam currents are measured by the four current transformers (FCT and DCCT; see Fig. 3) for both a pulsed and a dc beam.

For the beam position, there are two beam position monitors (strip line BPMs, Fig. 3); both have horizontal and vertical planes and are located inside the superconducting magnet. The distance between these two BPMs is $1.54 \mathrm{~m}$. Both the electron beam and proton beam position can be measured by these BPMs, and they are used for the initial electron and proton beam alignment. A novel new electron backscattering detector (eBSD) [43] on the gun side is designed for a precise overlap alignment of the electron and proton beams.

Outside the entrance of the collector, four quadrant scrapers [24] are used to help align the electron beam into the collector. By steering the beam horizontally (CSX) or vertically (CSY) to both sides until there is a beam signal on one of the scrapers, the center of the electron 
beam can be estimated by the average of the CSX and CSY current.

Variations of the cathode bias power supply current are used as a beam current loss measurement. If there is any electron beam loss between the cathode and the collector in the vacuum, the lost current is compensated from the ground. For this compensated current, the cathode bias power supply provides the only path (see Fig. 3). If the absolute current in the cathode bias is over $5 \mathrm{~mA}$, the electron beam will be turned off by the RHIC electron lenses machine protection system.

The profile of the electron beam is measured by means of two insertion devices: a YAG screen and a pinhole detector [24]. The anode voltage is measured locally by the electron beam modulator, which is close to the electron gun. The anode voltage can be used for gun perveance calculation as well as providing a diagnostic signal on an oscilloscope.

Ion accumulation in the interaction region within the superconducting solenoid was one of the concerns when the electron lens was designed. A biased drift-tube system (DT01-05) with a high-voltage gradient is designed to extract any accumulated ions from the interaction region [44]. The extracted ion current is measured by the ion collector (Fig. 3). So far, no signal was seen on the ion collector, during either commissioning or operation.

\section{COMMISSIONING AND OPERATION}

\section{A. Longitudinal alignment}

The electron lenses were commissioned parasitically to RHIC physics operation before they were used for head-on beam-beam compensation. In 2014, we aligned the electron beam with the hadron beam to gain the first experience with electron-hadron beam-beam interactions. The demonstration of the electron and gold beam overlap was achieved by use of the eBSD [43]. In the parasitic commissioning mode, the $78 \mathrm{kHz}$ pulsed electron beam can be propagated through the interaction region such that it does not interact with the RHIC beam.
As mentioned in Ref. [24], the parasitic mode needs a fast rise and fall time for the electron beam pulse to align with the abort gap [24] and thus avoid interacting with the circulating ion beam. The 5\%-95\% rise and fall time (50 ns) has been measured via the anode voltage waveform as well as the BPM response time. Both are shown in Fig. 13.

During the commissioning, the electron beam was first aligned with the ion beam abort gap [24], as shown in Fig. 14 for the yellow beam. In Fig. 14, the yellow ion beam abort gap is shown by the RHIC fill pattern in the bottom trace. One $e$-beam trigger (Fig. 14, trace 2 ) was first pulsed, and then the resulting anode voltage pulse (trace 3 ) was measured on the anode. The electron beam was measured via the drift tube DT04 in Fig. 3 and shown with the top green trace (trace 4) in Fig. 14, between the two red vertical lines. This shows the electron beam was aligned within the yellow ion beam abort gap (traces 1 and 4).

After the alignment with the ion beam abort gap, the electron beam could be operated and commissioned while the ion beam was circulating. Figure 15 shows the RHIC ion beam intensity and the anode modulator power supply currents for both electron lenses. The electron beam ran for several hours without affecting the ion beam. The lack of a disturbance in the ion beam indicates that the electron beam was placed within the beam abort gap, while the modulator power supply current $(140 \mathrm{~mA})$ indicates that both electron beams were running in the parasitic mode. When the $e$ lenses were running with the dc mode, the modulator power supply current was negligible.

The electron beam can be moved earlier in time to collide with the ion beam. Figure 16 shows the ion beam losses for the last several bunches that collided with the electron beam. The red trace is the anode voltage representing the electron beam current. The last (bunch 111) and the second to last bunch (bunch 110) had a clear response to the change in electron beam current, while the fourth (bunch 108) from the last shows no response to the electron beam. The third bunch (bunch 109) from the last has higher losses than the others. These higher losses could be reduced by further adjusting the electron beam timing.

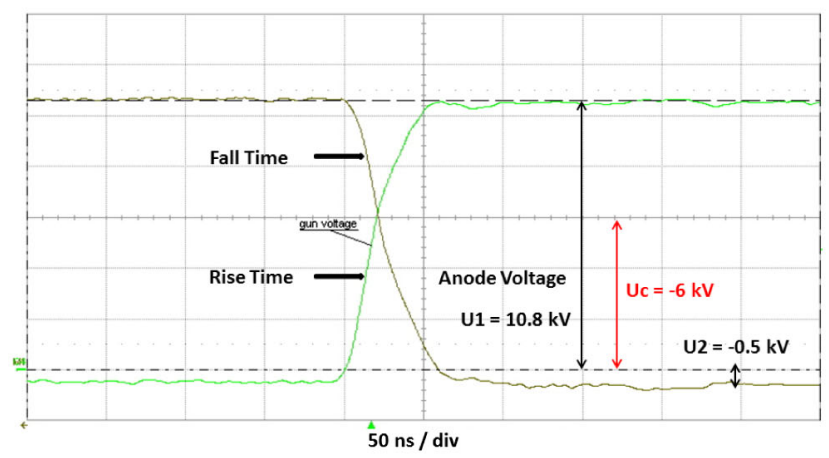

FIG. 13. Beam rise and fall time measurement via the anode voltage (left) and signals from the four BPM electrodes (right). 


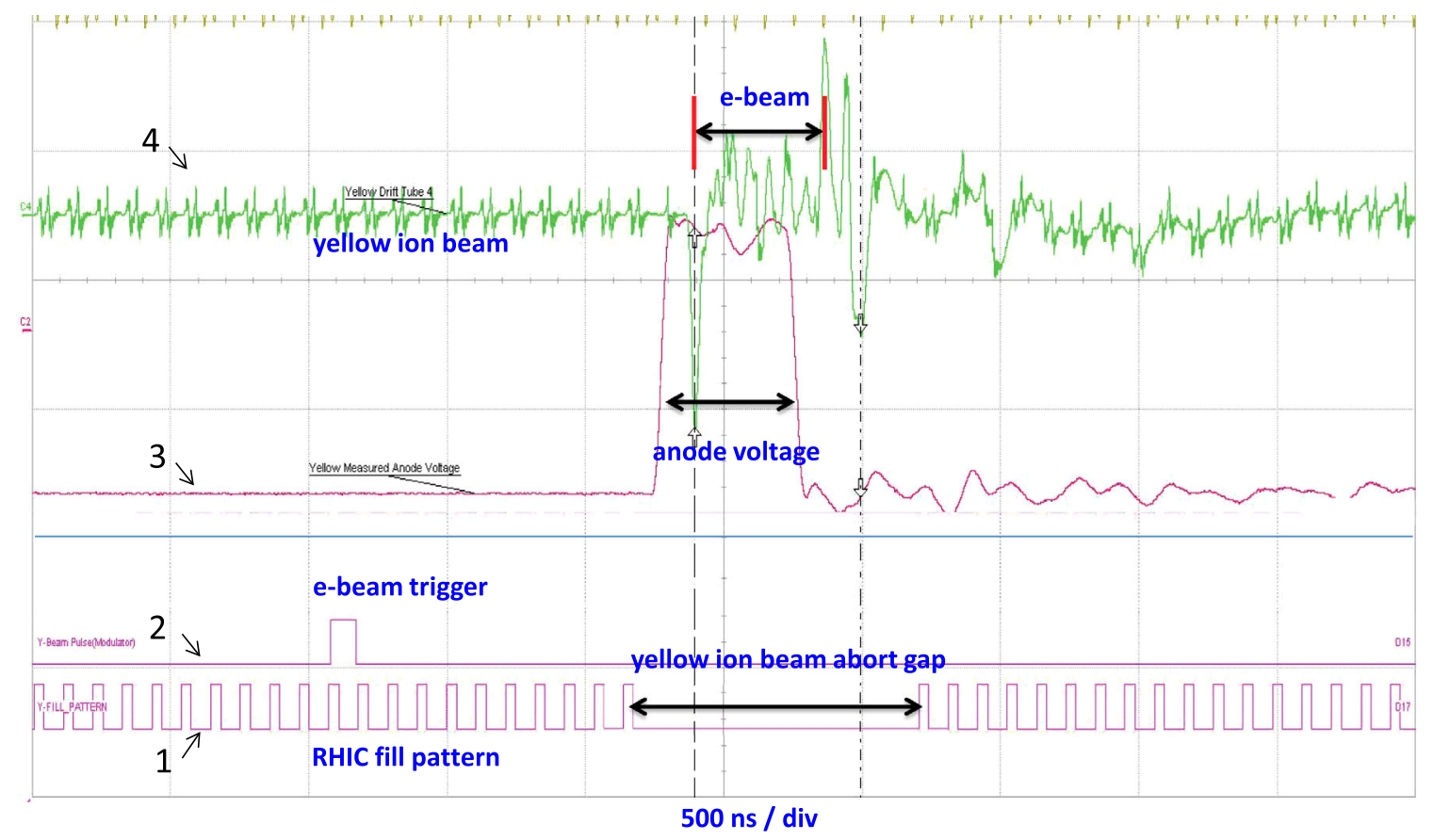

FIG. 14. Longitudinal alignment of the electron beam pulse within the ion beam abort gap.

The ability of aligning the electron beam with the last several bunches (nominal was the last two bunches) means more commissioning time with a negligible effect on machine luminosity. Then the electron lens could be used for transverse alignment and other beam-beam studies.

\section{B. Transverse alignment}

The demonstration of electron and ion beam overlap was achieved via the eBSD [43] during the commissioning. Figure 17 shows the blue eBSD signal as a function of the ion beam position. Both the horizontal and vertical eBSD signals are fitted very well with Gaussian distributions.

The blue electron gun is located outside of the ring with a positive position within the RHIC coordinate system. And

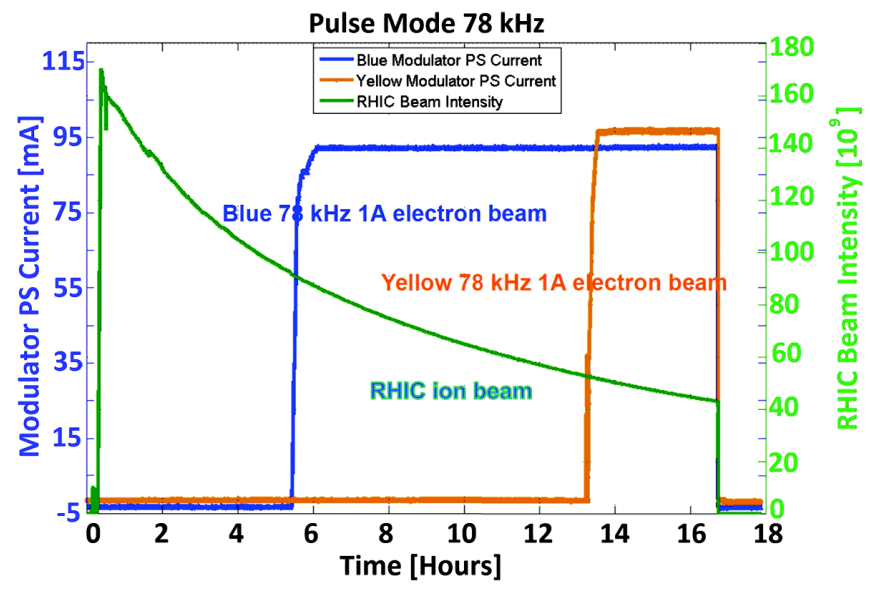

FIG. 15. Anode modulator signals and ion beam intensity during the parasitic mode. the two horizontal data points on the right bottom corner indicate this asymmetry of the electron beam trajectory with respect to the RHIC ring [43].

\section{Operation in the 2015 run}

At the beginning of the 2015 RHIC $100 \mathrm{GeV}$ polarized proton run, the two electron lenses were ready for operation. They were used for 112 stores without any failure to turn on. The electron lenses were turned on following several steps as shown in Fig. 18.

At the beginning of the ion beam energy ramp ( $0 \mathrm{~s}$ from the start of ramp), there are no horizontal bumps, but $\pm 5 \mathrm{~mm}$ vertical bumps at all IPs for the blue and yellow

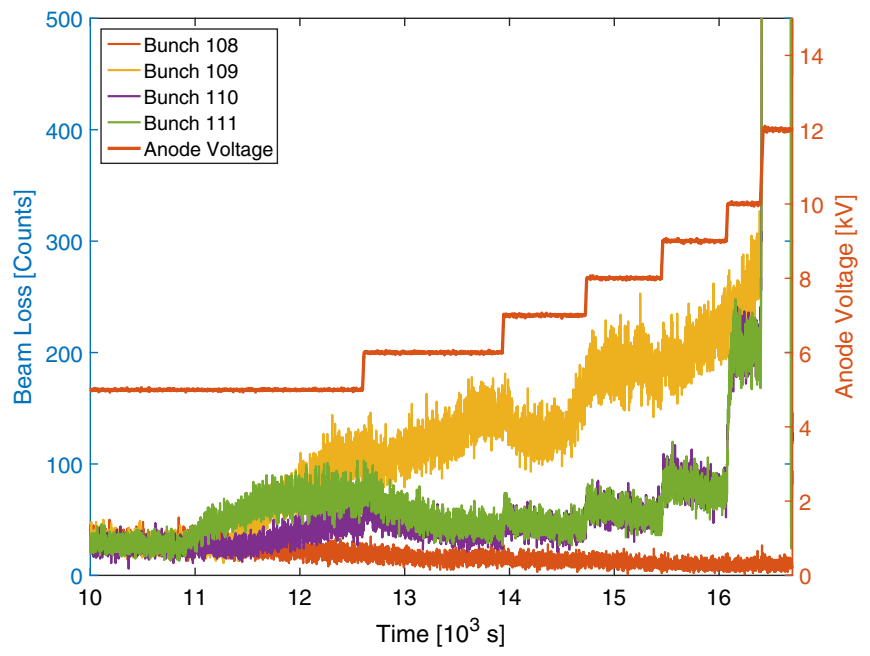

FIG. 16. Alignment and collision with the last several bunches. 


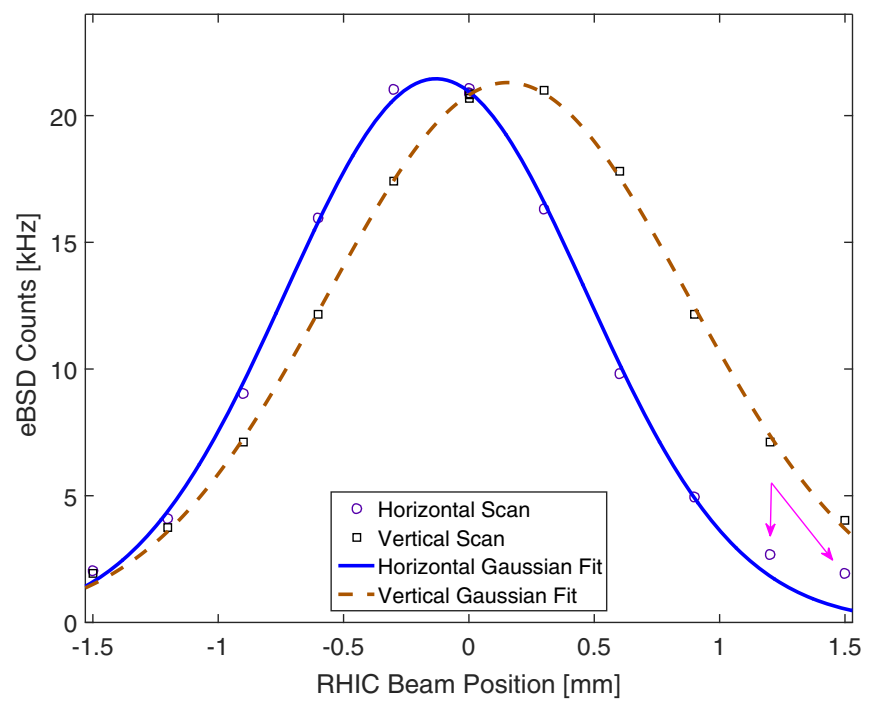

FIG. 17. Demonstration of the electron and ion beam overlap.

beam. From 165 to $175 \mathrm{~s}$, the vertical bump at IP6 and IP8 was changed to $\pm 4 \mathrm{~mm}$, to prepare for a bump collapse. Meanwhile, there were $\pm 5 \mathrm{~mm}$ horizontal bumps created at IP10 to avoid the ion beam collision with the electron beam.

Then, $300 \mathrm{~s}$ after the beginning of the ramp (reaching storage energy), the electron beam current was increased to its nominal operational current of $500 \mathrm{~mA}$ for the blue electron lens and $650 \mathrm{~mA}$ for the yellow electron lens.

We experienced an electron beam instability issue with blue electron beam currents greater than $750 \mathrm{~mA}$ [27], with the symptoms of gun vacuum spike and electron beam current drop. After inspecting the gun during RHIC shutdown, the ceramic close to the anode and the cathode was found to be contaminated. Reflected electrons from the collector, caused by the electron beam striking the collector at a large angle, could be another reason.

The static bump amplitudes for all IPs between 175 and $1180 \mathrm{~s}$ are shown in Fig. 19. From 1180 to $1195 \mathrm{~s}$, the vertical bump at IP6 was removed, first at the spectral transmissometer and radiometer (STAR); then $5 \mathrm{~s}$ later, both the vertical bumps at IP8 and the horizontal bump at IP10 were removed at the same time: The beams went into collision in the PHENIX and in the electron lenses simultaneously. All the above bumps were removed via the existing RHIC beam orbit feedback system, and no additional commissioning time for IP10 was needed.

After establishing collisions at IP6, IP8, and IP10, the RHIC luminosity and IR steering application (LISA) [45] program started optimizing collision rates for these three collision points. Then, the goal orbits were saved and used for auto orbit correction, which is repeated regularly to compensate for orbit drifts during store.

Approximately $1 \mathrm{~h}$ after the beginning of the store, the lenses were gradually ramped down (Fig. 20) as the beambeam parameters are reduced to values that could be supported by the lattice alone. During the ramp down period, the lattice tune was also changed accordingly to compensate for the linear tune shift introduced by the electron lenses.
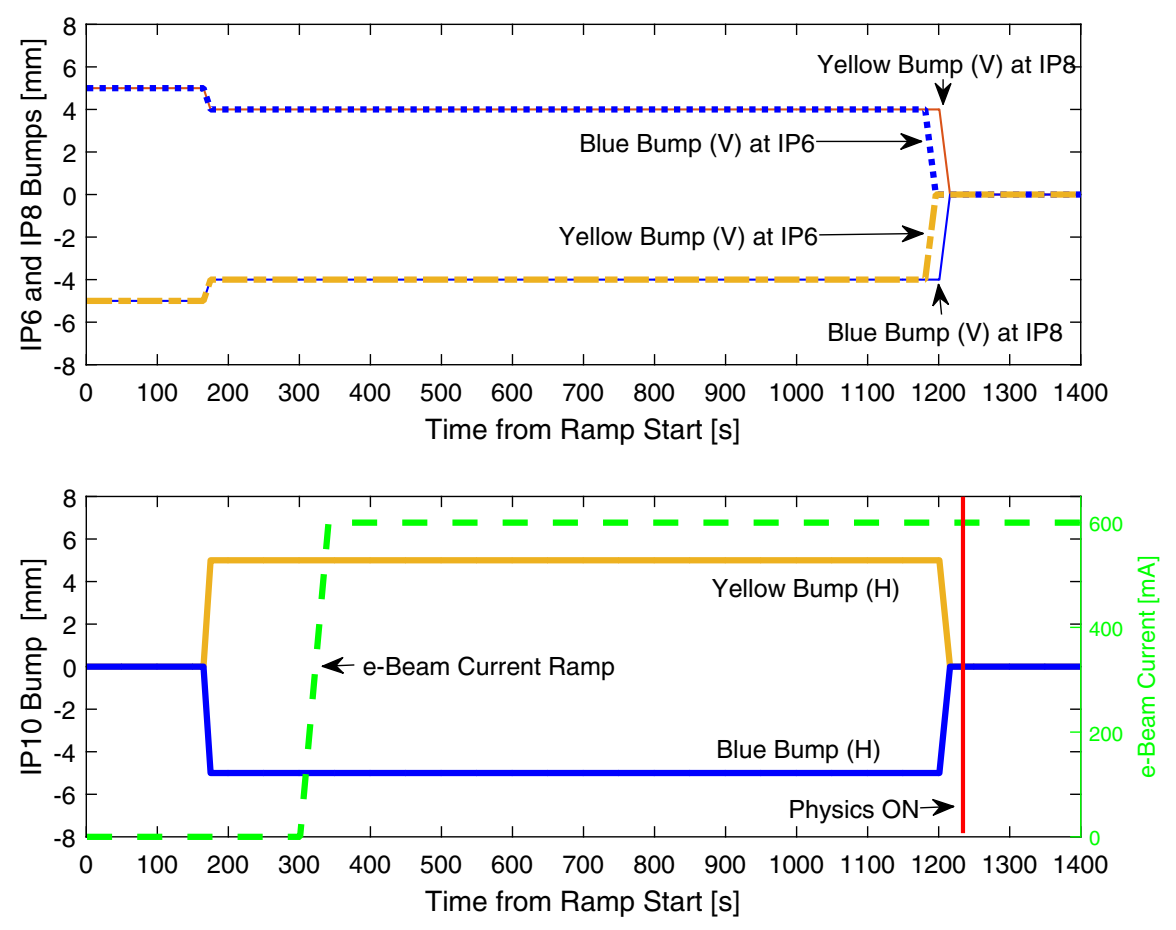

FIG. 18. Separation bumps and electron beam current. 

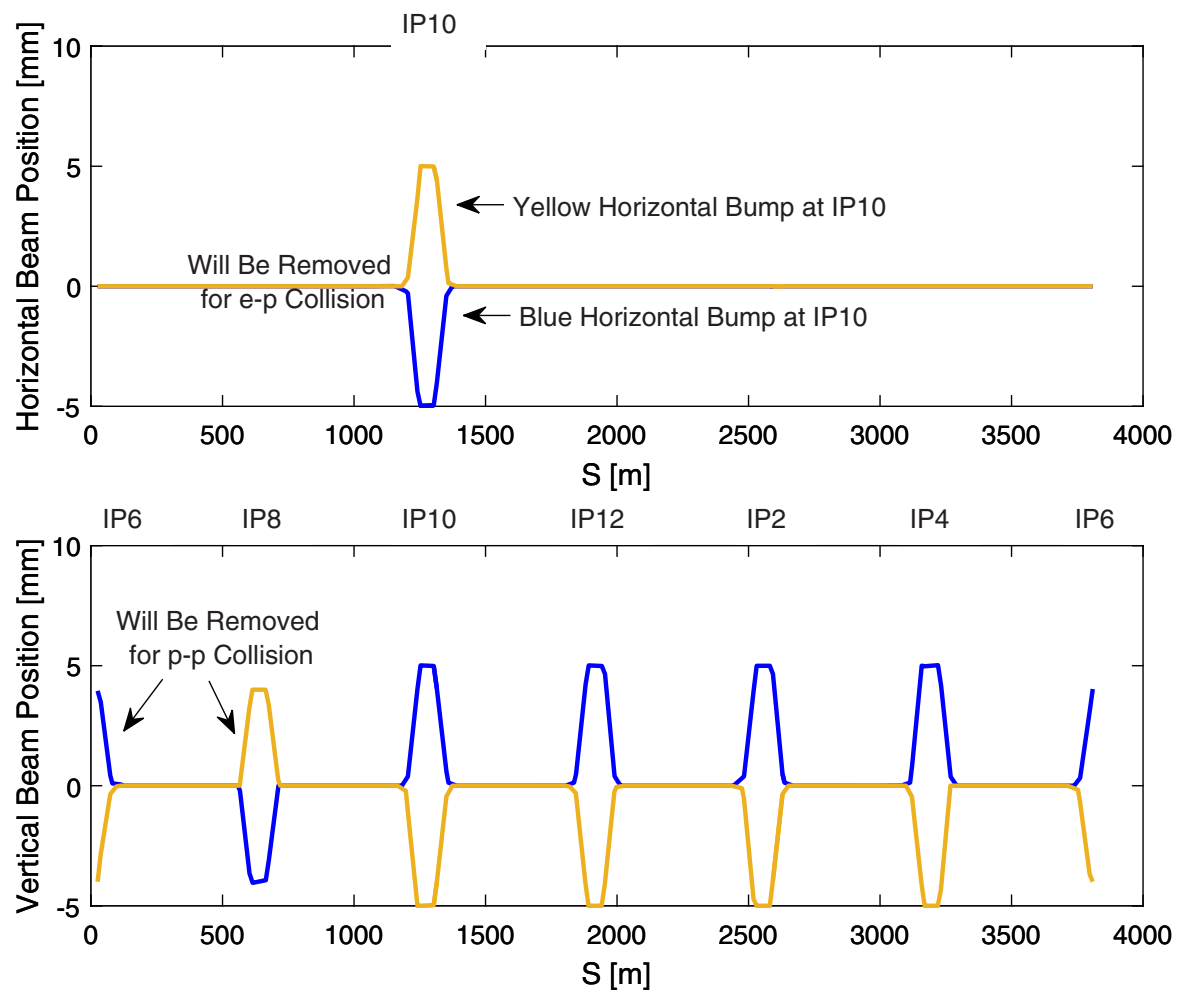

FIG. 19. Separation bump around the rings.
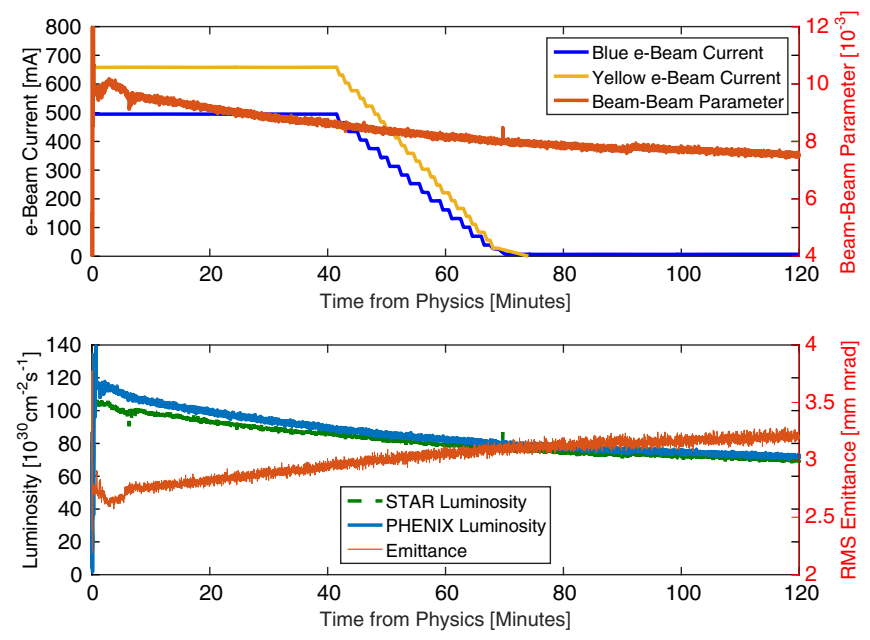

FIG. 20. Typical store with an electron lens.

\section{BEAM-BEAM EXPERIMENTS}

Besides the 2015 RHIC operation, the electron lenses were also used for beam-beam experiments, such as the linear tune shift measurement [27] and incoherent tune spread compensation [1].

To demonstrate the reduction of incoherent beam-beam tune spread due to the electron lens, one can use the transverse beam transfer function. Although successful in simulations [46], the incoherent tune distribution with $\mathrm{p}+\mathrm{p}$ collisions could not be extracted due to strong coherent modes. In $\mathrm{p}+\mathrm{Al}$ collisions, however, coherent modes were suppressed due to a large tune separation between the blue and yellow beams.

During the $\mathrm{p}+\mathrm{Al}$ operation, there was a $3.25 \mathrm{mrad}$ crossing angle offset and a $16.2 \mathrm{~mm}$ position offset in the horizontal plane because of the asymmetric beams [47]. Therefore, the electron beam position and angle needed to be moved closer to the ion beam first. Figure 21 shows how the

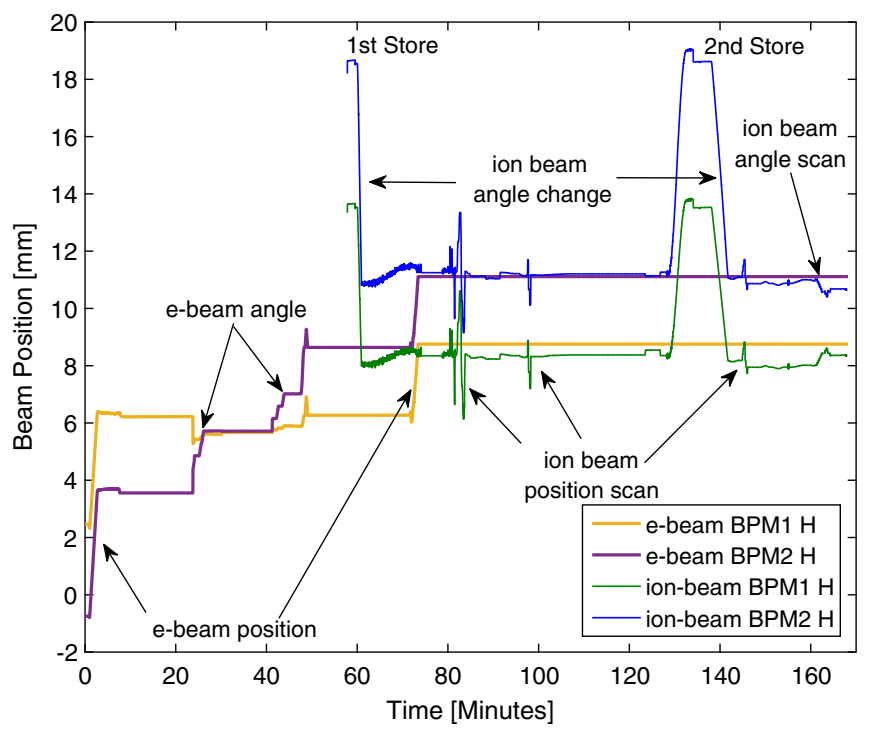

FIG. 21. Blue electron beam and ion beam alignment procedure for the horizontal plane. 
electron beam was moved close to the ion beam by using BPMs and then how fine alignment was achieved with the eBSD. The alignment was done by following the steps shown in Fig. 21. For the vertical plane, the same procedure was followed but with less angle and position offset.

During the alignment procedure, the average electron beam position was moved from 0.9 to $7.5 \mathrm{~mm}$ initially by changing (reducing) the blue GSB current, as well as the GSX and CSX for the beam trajectory adjustment. The electron beam angle was changed from -2.09 to $1.54 \mathrm{mrad}$ by the long and short superconducting correctors. The long horizontal superconducting corrector can change the electron beam angle by $2 \mathrm{mrad}$ for a $3 \mathrm{~T}$ main magnetic field. Then, the rest of the beam angle change was achieved by the five short correctors, even though they were designed only for correcting magnetic field straightness.

After that, the first $\mathrm{p}+\mathrm{Al}$ store was put up, and the ion beam angle was reduced from 3.25 to $1.89 \mathrm{mrad}$, which is the minimum angle for the $\mathrm{Al}$ beam without any visible beam loss. Meanwhile, its average position was changed from 16.2 to $9.8 \mathrm{~mm}$ because of the angle change

At this moment, the horizontal separation bumps at IP10 were removed for the $\mathrm{e}+\mathrm{Al}$ collision. Then both the BPMs and the eBSD signal were used to monitor the electron beam position movement from 7.5 to $9.9 \mathrm{~mm}$. Thereafter, the alignment proceeded with the ion beam position scan via the LISA application, which uses the eBSD signal as an optimizing signal [43].

Following that, the second $\mathrm{p}+\mathrm{Al}$ store was ramped up for the final alignment. It also included the same angle change for $\mathrm{Al}$ at the beginning of the second store and is followed by a LISA position scan. The angle alignment was also executed by the LISA angle scan, which changed the ion beam angle from 1.89 to $1.50 \mathrm{mrad}$.

Thereafter, the beam-beam experiment could be started and the incoherent tune distribution due to the $e$-lenses could be measured. Figure 22 illustrates that the Al beam incoherent tune distribution changes with the different

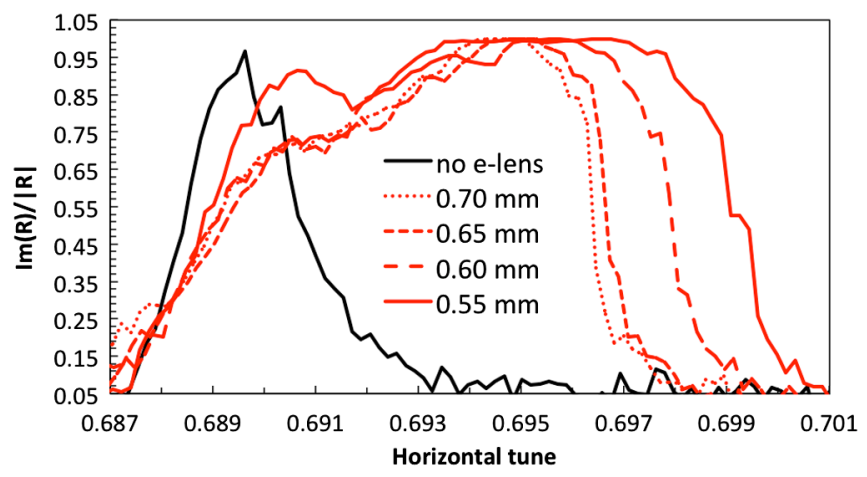

FIG. 22. Incoherent tune distributions for various electron beam sizes and an electron beam current of $900 \mathrm{~mA}$. The beam distributions are measured with beam transfer functions and are aligned to the left with an offset for better visibility of the effect. electron beam sizes. During this measurement, the Al beam was collided only with the electron beam, and there was no other beam-beam contribution at IP6 or IP8.

Figure 22 shows that a smaller electron beam size results in a larger incoherent tune spread. More information about the beam-beam experiment results can be found in Refs. [1,28]. During the experiment, the electron beam energy was $5 \mathrm{keV}$ with $900 \mathrm{~mA}$ electron beam current. The superconducting solenoid field was $3 \mathrm{~T}$.

\section{MACHINE PROTECTION AND RELIABILITY}

Machine protection was another important part of the electron lens system. The inputs for the machine protection system included the status of all power supplies, their current or voltage loss, vacuum pressure and valves status, water flow and water temperature of warm solenoids, global electron beam loss, beam losses on the eBSD tungsten blocks [43], and the status of the high-voltage switches. For the YAG screen and pinhole protection, there is another input to limit the beam pulse frequency and pulse width. To prevent the dark dc beam current, the anode bias voltage measurement provides another input to turn off the electron beam trigger and set the anode drift tube (DT00 in Fig. 3) from the ground potential to the cathode potential via another high-voltage switch. The machine protection system has protected the electron lens system successfully, and no damage occurred during operations.

The reliability and availability of the RHIC electron lens system were high. The electron lenses were turned on for every store. They did not fail during the run except for one collector power supply trip during a store ramp up. The electron beam was recovered within several minutes after this trip.

\section{SUMMARY}

In this paper, the design considerations for the RHIC electron lens system were presented. Most electron beam parameters were measured and satisfied the specified requirements.

During design and commissioning, the $1 \mathrm{~A}$ dc electron beam current requirement for both 100 and $250 \mathrm{GeV}$ proton beam has been achieved with less than $12 \mathrm{kV}$ anode voltages. Smooth transverse beam profile is another critical factor of successful beam-beam compensation. The measured electron beam transverse profile for a $4.1 \mathrm{~mm}$ radius cathode (for a $250 \mathrm{GeV}$ proton beam) and a $7.5 \mathrm{~mm}$ radius cathode (for a $100 \mathrm{GeV}$ proton beam) could be fitted to Gaussian distributions very well.

The field and straightness of the superconducting magnets were also measured and satisfied the deviation requirement of $\pm 50 \mu \mathrm{m}$ within a $\pm 850 \mathrm{~mm}$ range. This ensures there is enough good field for an electron beam and proton beam overlap. The $6 \mathrm{~T}$ magnetic field was achieved during 2015 operation. 
The electron beam position jitter was calculated to be $3 \mu \mathrm{m}$ with a magnet current ripple specification of $10^{-4}$, while the requirement is $9 \mu \mathrm{m}$. The achievement of $0.1 \%$ current ripple requirement had been demonstrated via anode voltage measurements on the RHIC $e$-lens test bench [24]. Direct current ripple measurements are planned in the future.

The transverse fine alignment was achieved with the eBSD [43], which is a new system used as the main diagnostic for accurately aligning the electron and ion beams in the RHIC $e$-lenses. The maximum displacement of $0.028 \mathrm{~mm}$ between the electron beam and ion beam has been demonstrated [43], which is less than $10 \%$ of the rms beam size requirement (for a $250 \mathrm{GeV}$ proton beam).

From above, we see that the electron beam current, beam profile, eBSD signal, and all other hardware are compatible with the $250 \mathrm{GeV}$ operations as well as $100 \mathrm{GeV}$ operations.

At the end of the paper, the operation procedure and a beam-beam experiment about incoherent tune distribution with $e$-lenses are presented.

All the above electron beam characteristics as well as the $e$-lens lattice [18] ensure the success of the RHIC $e$-lenses for partial head-on beam-beam compensation leading to higher luminosities.

\section{ACKNOWLEDGMENTS}

The work was supported by many colleagues in the Collider-Accelerator Department and the Superconducting Magnet Division at Brookhaven National Laboratory. The authors also appreciate valuable discussions with the Fermi National Accelerator Laboratory Tevatron Electron Lens (FNAL TEL) staff, in particular, V. Shiltsev, A. Valishev, and G. Stancari. Work was supported by Brookhaven Science Associates, LLC under Contract No. DE-AC0298CH10886 with the U.S. Department of Energy.

[1] W. Fischer et al., Operational Head-on Beam-Beam Compensation with Electron Lenses in the Relativistic Heavy Ion Collider, Phys. Rev. Lett. 115, 264801 (2015).

[2] A. Zelenski, G. Atoian, D. Raparia, J. Ritter, and D. Steski, The RHIC polarized H-ion source, Rev. Sci. Instrum. 87, $02 B 705$ (2016).

[3] Y. Luo, W. Fischer, N. P. Abreu, X. Gu, A. Pikin, and G. Robert-Demolaize, 6-D weak-strong simulation of head-on beam-beam compensation in the Relativistic Heavy Ion Collider, Phys. Rev. ST Accel. Beams 15, 051004 (2012).

[4] V. H. Ranjbar et al., in Proceedings of the 4th International Particle Accelerator Conference, IPAC-2013, Shanghai, China, 2013 (JACoW, Shanghai, China, 2013), pp. 15441546.

[5] V. Schoefer et al., RHIC polarized proton-proton operation at $100 \mathrm{GeV}$ in run 15, in Proceedings of IPAC2015, Richmond, VA, 2015 (JACoW, Richmond, 2015), pp. 2384-2386.
[6] M. Bergher et al., Status report on D.C.I., IEEE Trans. Nucl. Sci. 26, 3559 (1979).

[7] V.D. Shiltsev, Electron Lenses for Super-Colliders (Springer, New York, 2016).

[8] V. Shiltsev, V. Danilov, D. Finley, and A. Sery, Considerations on compensation of beam-beam effects in the Tevatron with electron beams, Phys. Rev. ST Accel. Beams 2, 071001 (1999).

[9] E. N. Tsyganov, A. Taratin, and A. I. Zinchenko, CERN Report No. SL-Note-95-116-AP, 1995.

[10] V. Shiltsev et al., Tevatron electron lenses: Design and operation, Phys. Rev. ST Accel. Beams 11, 103501 (2008).

[11] V. Shiltsev, Y. Alexahin, K. Bishofberger, V. Kamerdzhiev, V. Parkhomchuk, V. Reva, N. Solyak, D. Wildman, X.-L. Zhang, and F. Zimmermann, Experimental studies of compensation of beam-beam effects with Tevatron electron lenses, New J. Phys. 10, 043042 (2008).

[12] V. Shiltsev, Y. Alexahin, K. Bishofberger, V. Kamerdzhiev, G. Kuznetsov, and X.-L. Zhang, Experimental Demonstration of Colliding-Beam-Lifetime Improvement by Electron Lenses, Phys. Rev. Lett. 99, 244801 (2007).

[13] X. Zhang, K. Bishofberger, V. Kamerdzhiev, V. Lebedev, V. Shiltsev, R. Thurman-Keup, and A. Tollestrup, Generation and diagnostics of uncaptured beam in the Fermilab Tevatron and its control by electron lenses, Phys. Rev. ST Accel. Beams 11, 051002 (2008).

[14] G. Stancari and A. Valishev, Beam-beam compensation studies in the Tevatron with electron lenses, in Proceedings of the ICFA Mini-Workshop on Beam-Beam Effects in Hadron Colliders (BB2013), CERN, Geneva, Switzerland, 2013 (JACoW, Geneva, 2013), pp. 121-125.

[15] G. Stancari, A. Valishev, G. Annala, G. Kuznetsov, V. Shiltsev, D. A. Still, and L. G. Vorobiev, Collimation with Hollow Electron Beams, Phys. Rev. Lett. 107, 084802 (2011).

[16] G. Stancari, V. Previtali, and A. Valishev, Conceptual design of hollow electron lenses for beam halo control in the Large Hadron Collider, arXiv:1405.2033.

[17] G. Stancari, K. Carlson, M. W. McGee, L. E. Nobrega, A. L. Romanov, J. Ruan, and A. Valishev, Electron lenses for experiments on nonlinear dynamics with wide stable tune spreads in the fermilab integrable optics test accelerator, in Proceedings of IPAC2015, Richmond, VA, 2015 (JACoW, Richmond, 2015), pp. 46-49, MOBC3.

[18] W. Fischer, X. Gu, M. Blaskiewicz, K. A. Drees, C. Liu, Y. Luo, A. Marusic, R. Michnoff, T. A. Miller, M. Minty, C. Montag, A. I. Pikin, G. Robert-Demolaize, V. Schoefer, and P. Thieberger (unpublished).

[19] A. I. Pikin et al., Structure and design of the electron lens for RHIC, in Proceedings of the 24th Particle Accelerator Conference, PAC-2011, New York, 2011 (IEEE, New York, 2011), pp. 2309-2311 (2011).

[20] X. Gu et al., Designing a beam transport system for RHIC's electron lens, in Proceedings of the 24th Particle Accelerator Conference, PAC-2011, New York, 2011 (IEEE, New York, 2011), pp. 1205-1207.

[21] R. Gupta et al., Magnetic design of e-lens solenoid and corrector system for RHIC, in Proceedings of the 24th Particle Accelerator Conference, PAC-2011, New York, 2011 (IEEE, New York, 2011), pp. 1130-1132. 
[22] T. Miller et al., Beam profile measurements in the RHIC electron lens using a pinhole detector and YAG screen, in Proceedings of IBIC 2014, Monterey, CA, 2014 (JACoW, California, 2014), pp. 59-63, MOPF08.

[23] V. Shiltsev, Y. Alexahin, K. Bishofberger, V. Kamerdzhiev, V. Parkhomchuk, V. Reva, N. Solyak, D. Wildman, X.-L. Zhang, and F. Zimmermann, Experimental studies of compensation of beam-beam effects with Tevatron electron lenses, New J. Phys. 10, 043042 (2008).

[24] X. Gu et al., The electron lens test bench for the Relativistic Heavy Ion Collider at Brookhaven National Laboratory, Nucl. Instrum. Methods Phys. Res., Sect. A 743, 56 (2014).

[25] G. I. Kuznetsov, IrCe cathodes for EBIS, J. Phys. Conf. Ser. 2, 35 (2004).

[26] G. I. Kuznetsov, High temperature cathodes for high current density, Nucl. Instrum. Methods Phys. Res., Sect. A 340, 204 (1994).

[27] X. Gu et al., RHIC electron lenses upgrades, in Proceedings of IPAC2015, Richmond, VA, 2015 (JACoW, Richmond, 2015), pp. 3830-3832.

[28] W. Fischer et al., RHIC performance with stochastic cooling for ions and head-on beam-beam compensation for protons, in Proceedings of IPAC2016, BEXCO, Busan Korea (JAoW, Busan, 2016), pp. 2055-2060, WEZA01.

[29] http://www.fieldp.com/.

[30] A. W. Chao and M. Tigner, Handbook of Accelerator Physics and Engineering (World Scientific, Singapore, 1999), p. 100.

[31] C. D. Child, Discharge from Hot CaO, Phys. Rev. 32, 492 (1911).

[32] I. Langmuir, The Effect of Space Charge and Initial Velocities on the Potential Distribution and Thermionic Current between Parallel Plane Electrodes, Phys. Rev. 21, 419 (1923).

[33] M. Reiser, Theory and Design of Charged Particle Beams, second, updated, expanded edition (Wiley-VCH Verlag, Weinheim, 2008), pp. 173-176.

[34] X. Gu, Z. Altinbas, M. Costanzo, W. Fischer, D. M. Gassner, J. Hock, Y. Luo, T. Miller, Y. Tan, P. Thieberger, C. Montag, and A. I. Pikin, Transverse profile of the electron beam for the RHIC electron lensesNucl. Instrum. Methods Phys. Res., Sect. A 798, 36 (2015).

[35] http://www.cobham.com/.
[36] A. Jain, in Proceedings of the International Magnetic Measurement Workshop 2015, Hsinchu, Taiwan (unpublished).

[37] M. Anerella et al., Mechanical design and construction of superconducting e-lens solenoid magnet system for RHIC head-on beam-beam compensation, IEEE Trans. Appl. Supercond. 24, 4101804 (2014).

[38] J. Muratore, D. Bruno, J. Escallier, W. Fischer, G. Ganetis, R. Gupta, A. Jain, P. Joshi, and P. Wanderer, Test results for the electron lens superconducting magnets at RHIC, IEEE Trans. Appl. Supercond. 24, 4100505 (2014).

[39] D. Bruno et al., Overview of the RHIC e-lens superconducting magnet power supply system, in Proceedings of the 25th Particle Accelerator Conference, PAC-2013, Pasadena, CA, 2013 (IEEE, New York, 2013), pp. 943945, WEPHO05.

[40] S. Humphries, Charged Particle Beams (Wiley, New York, 1990).

[41] A. V. Burov, G. W. Foster, and V. D. Shiltsev, Report No. FERMILAB-TM-2125, 2000.

[42] J. Alessi et al., The Brookhaven National Laboratory electron beam ion source for RHIC, Rev. Sci. Instrum. 81, 02A509 (2010).

[43] P. Thieberger et al., High energy Coulomb-scattered electrons for relativistic particle beam diagnostics, Phys. Rev. Accel. Beams 19, 041002 (2016).

[44] T. Miller, W. Fischer, D. M. Gassner, X. Gu, A. I. Pikin, S. Polizzo, P. Thieberger, and J. Barth, Design and performance of the biased drift tube system in the BNL electron lens, in Proceedings of the International Beam Instrumentation Conference (IBIC 2013), Oxford, UK, 2013 (JACoW, Oxford, 2013), pp. 291-294.

[45] A. Drees and Ted D'Ottavio, Luminosity optimization using automated IR steering at RHIC, in Proceedings of the 9th European Particle Accelerator Conference, Lucerne, 2004 (EPS-AG, Lucerne, 2004), p. 911, MOPLT163.

[46] P. Görgen, O. Boine-Frankenheim, and W. Fischer, Beam transfer functions for relativistic proton bunches with beam-beam interactions, Nucl. Instrum. Methods Phys. Res., Sect. A 777, 43 (2015).

[47] C. Liu et al., RHIC operation with asymmetric collisions in 2015, in Proceedings of IPAC2016, 2016, BEXCO, Busan Korea (JAoW, Busan, 2016), pp. 1527-1529, tupmw038. 